\title{
Light Cross-Linkable Marine Collagen for Coaxial Printing of a 3D Model of Neuromuscular Junction Formation
}

\author{
Borja Sanz ${ }^{\dagger}$, Ane Albillos Sanchez ${ }^{\dagger}$, Bonnie Tangey, Kerry Gilmore, Zhilian Yue, Xiao Liu and Gordon Wallace ${ }^{*}$ \\ ARC Centre of Excellence for Electromaterials Science, Intelligent Polymer Research Institute, AIIM Facility, \\ Innovation Campus, University of Wollongong, Squires Way, Wollongong, New South Wales 2500, Australia; \\ bs540@uowmail.edu.au (B.S.); aas922@uowmail.edu.au (A.A.S.); btangey@uow.edu.au (B.T.); \\ kerryg@uow.edu.au (K.G.); zyue@uow.edu.au (Z.Y.); xiaol@uow.edu.au (X.L.) \\ * Correspondence: gwallace@uow.edu.au \\ + Current address: Department of Orthopedics, University Medical Center Utrecht, Utrecht 3508 GA, \\ The Netherlands.
}

Citation: Sanz, B.; Albillos Sanchez, A.; Tangey, B.; Gilmore, K.; Yue, Z.; Liu, X.; Wallace, G. Light CrossLinkable Marine Collagen for Coaxial Printing of a 3D Model of Neuromuscular Junction Formation. Biomedicines 2021, 9, 16 https://dx.doi.org/10.3390/ biomedicines 9010016

Received: 15 December 2020 Accepted: 22 December 2020 Published: 26 December 2020

Publisher's Note: MDPI stays neutral with regard to jurisdictional claims in published maps and institutional affiliations.

Copyright: (C) 2020 by the authors. Licensee MDPI, Basel, Switzerland. This article is an open access article distributed under the terms and conditions of the Creative Commons Attribution (CC BY) license (https: / / creativecommons.org/ licenses/by/4.0/).

\begin{abstract}
Collagen is a major component of the extracellular matrix (ECM) that modulates cell adhesion, growth, and migration, and has been utilised in tissue engineering applications. However, the common terrestrial sources of collagen carry the risk of zoonotic disease transmission and there are religious barriers to the use of bovine and porcine products in many cultures. Marine based collagens offer an attractive alternative and have so far been under-utilized for use as biomaterials for tissue engineering. Marine collagen can be extracted from fish waste products, therefore industry by-products offer an economical and environmentally sustainable source of collagen. In a handful of studies, marine collagen has successfully been methacrylated to form collagen methacrylate (ColMA). Our work included the extraction, characterization and methacrylation of Red Snapper collagen, optimisation of conditions for neural cell seeding and encapsulation using the unmodified collagen, thermally cross-linked, and the methacrylated collagen with UV-induced cross-linking. Finally, the 3D co-axial printing of neural and skeletal muscle cell cultures as a model for neuromuscular junction (NMJ) formation was investigated. Overall, the results of this study show great potential for a novel NMJ in vitro 3D bioprinted model that, with further development, could provide a low-cost, customizable, scalable and quick-to-print platform for drug screening and to study neuromuscular junction physiology and pathogenesis.
\end{abstract}

Keywords: 3D bioprinting; neural cell; skeletal muscle cell; neuromuscular junction

\section{Introduction}

Collagen is a major component of the extracellular matrix (ECM) and is the most abundant protein in the body [1-3]. In addition to providing structural support and tensile strength to tissues, collagen modulates cell adhesion, growth, and migration [3]. Due to its low immunogenicity and high biocompatibility, collagen has demonstrated biomedical applications in wound healing [4] as well as aiding periodontal [5] and bone and cartilage repair [6].

$3 \mathrm{D}$ bioprinting is a fast growing technique that enables precise fabrication of complex constructs containing multiple cells and biomaterials [7,8]. Our group, for example, has developed 3D brain-like structures, consisting of discrete layers of primary neural cells [9] and fabricated implantable 3D pancreatic Islet-containing constructs [10], using bioprinting strategies. 3D printed constructs, such as a multi-material prosthetic hand [11] and dental implants [12], have wide clinical applications. Despite its natural biocompatibility, both unmodified collagen and the product of collagen denaturation, gelatin, form hydrogels with low tensile strength that are susceptible to rapid degradation $[13,14]$ making them challenging biomaterials for use in 3D printing or implantation. To address this problem, chemical and physical methods of collagen and gelatin crosslinking have been developed, 
increasing the tunability of their mechanical properties. Enhancing crosslinking within the triple helical structure of collagen increases mechanical strength $[15,16]$ and has been shown to decrease the rate of degradation $[17,18]$. Traditional chemical approaches however have been associated with cytotoxicity due to the persistence of crosslinking agents like glutaraldehyde within collagen [15]. On the other hand, physical methods such as thermal and UV crosslinking can result in collagen denaturation [19]. In addition, UV irradiation alone is ineffective as it does not result in a high degree of crosslink formation [19]. Photo-crosslinkable collagen or gelatin methacrylate are commonly used biomaterials due to their intrinsic biocompatibility and mechanically tunable characteristics [20]. Collagen methacrylate is formed by coupling of methacrylate groups to the amine-containing side chains of collagen. In the presence of light and a photo-initiator, a polymerization crosslinking reaction can then be triggered [21]. The desired degree of crosslinking can be controlled by the degree of methacrylation, the concentration of collagen, as well as the UV intensity and duration, and the concentration of the photoinitiator, making collagen methacryloyl a flexible biomaterial for tissue engineering and 3D bioprinting.

Currently, collagen is most commonly extracted from terrestrial animals such as cows, pigs, and poultry [22]. The use of these collagens as biomaterials in tissue engineering applications is limited due to risk of transmission of zoonotic diseases, such as foot and mouth disease, bovine spongiform encephalopathy, and avian influenza [23]. There are also religious barriers to the use of bovine and porcine products in many cultures [24]. Marine-based collagens have so far been under-utilized, however there has been increasing interest in them in recent years [1,25], particularly for use as biomaterials for tissue engineering [26]. Marine collagens offer an attractive alternative due to their low risk of pathogen transmission and lack of religious constraints. In addition, marine collagen can be extracted from fish waste products such as skin [27,28], bones [29,30], scales [31-33], and viscera [34,35]. Collagen has already been extracted and characterised for a broad range of marine species including jellyfish [36,37], cuttlefish [38], sea sponges [39,40], and numerous fishes [32-35,41-46]. In a handful of studies, marine collagen has also successfully been methacrylated to form collagen or gelatin methacrylate $[20,26,47,48]$. Given that an estimated $50 \%$ of commercial fish weight is currently discarded as non-consumable waste [49], fish industry by-products offer an economical and environmentally sustainable source of collagen.

Neural stem and progenitor cells have been shown to proliferate and differentiate in hydrogels containing porcine [50], bovine [51], and rat tail collagens [52,53]. To our knowledge however, investigations into the potential use of marine collagens as biomaterials for neural cell 3D tissue engineering has so far been limited to a study showing differentiation of induced pluripotent (iPS) cells to the specific lineage of dorsal cortical neurons in collagen extracted from the fish species Tilapia [54]. With respect to methacrylated marine gelatin or collagen, the only work that has been reported has been with fibroblast cells $[20,26,47]$. We aimed to assess the potential for methacrylated collagen from the common fish, Red Snapper, to be used as a biomaterial for 3D bioprinting of neural cells. For this study we used ReNcell VM and NSC-34 cell lines. ReNcell VM is a human neural progenitor cell line extracted from the ventral mesencephalon of a developing brain and immortalized via retroviral transduction using the retrovirus v-myc. NSC-34 is a murine motor neuron-like cell line formed from the fusion of motor neuron-enriched primary embryonic spinal cord cells and N18TG2 neuroblastoma cells that can be differentiated in vitro. NSC-34 cells were used for this project because these cells express many of the morphological and physiological characteristics of primary motor neurons, such as process extension, acetylcholine synthesis and storage, action potential support, neurofilament protein expression, contact establishment with cultured myotubes, and induction of myotube twitching [55,56]. Additionally, previous studies showed that NSC-34 cells were able to induce AChR clustering on myotubes when they were co-cultured [56]. Moreover, these cells, unlike other neuronal cell lines, can adhere specifically to the leucine-arginine-glutamine (LRE) motif of s-laminin, 
a neuromuscular synapse-specific basal lamina glycoprotein [57]. This feature provides evidence that these hybrid cells uniquely express motor neuron phenotypic characteristics.

Our work included the extraction, characterization and methacrylation of Red Snapper collagen, optimisation of conditions for cell seeding and encapsulation using the unmodified collagen, thermally cross-linked, and the methacrylated collagen with UV-induced cross-linking. Finally, the 3D co-axial printing of neural and skeletal muscle cell cultures, as a model for neuromuscular junction formation, was investigated.

\section{Materials and Methods}

\subsection{Collagen Extraction and Purification}

Collagen was extracted from the skin of Red Snapper, obtained from the Better Choice Fisheries, North Wollongong of NSW, Australia under sterile conditions. The skin was washed, cut into small pieces and suspended in $1 \mathrm{~mL}$ of $100 \mathrm{mM}$ acetic acid (All reagents were from Sigma-Aldrich (Macquarie Park, NSW. Australia), if not differently specified) solution for every $60 \mathrm{mg}$ of fish skin. The $\mathrm{pH}$ was adjusted to 2.5 by adding $1 \mathrm{M}$ or $5 \mathrm{M} \mathrm{HCl}$ dropwise and the mixture reacted overnight with gentle stirring at $4{ }^{\circ} \mathrm{C}$. The insoluble material was removed by centrifugation at $5500 \times g$ for $1 \mathrm{~h}$. To separate the collagen from other proteins, $4.4 \mathrm{M}$ of $\mathrm{NaCl}$ solution was added with intermittent gentle mixing, until the final concentration of $\mathrm{NaCl}$ reached $0.7 \mathrm{M}$. The precipitation was left to proceed overnight and the precipitate collected by centrifugation at $5000 \times g$ for $30 \mathrm{~min}$. The collagen precipitate was solubilized in $500 \mathrm{mM}$ acetic acid to stabilize. The product was dialyzed, firstly against $500 \mathrm{mM}$ acetic acid at pH 2.5 overnight with gentle stirring. After filtration the sample was dialyzed against a $20 \mathrm{mM}$ acetic acid solution for a further $24 \mathrm{~h}$, replacing the solvent every 3-4 h, for a total of 3-4 times. Finally, the sample was dialyzed against cold deionized water for $1-2 \mathrm{~h}$, before freeze drying and storing at $-30{ }^{\circ} \mathrm{C}$.

\subsection{Methacrylation of Collagen}

Collagen was dissolved in $20 \mathrm{mM}$ acetic acid, to a final concentration of $2.5 \mathrm{mg} / \mathrm{mL}$. The salt concentration was adjusted to $200 \mathrm{mM} \mathrm{NaCl}$ and the $\mathrm{pH}$ adjusted to 7.4 using $1 \mathrm{M}$ $\mathrm{NaOH}$ at $0.023 \times$ the volume of collagen. Methacrylic anhydride was added to target the residues of lysine and hydroxylysine with $52 \mu \mathrm{L}$ of methacrylic anhydride added to every $100 \mathrm{mg}$ of collagen. The reaction was carried out at $4{ }^{\circ} \mathrm{C}$ for $24 \mathrm{~h}$ and the product (ColMA) was dialyzed against $20 \mathrm{mM}$ acetic acid for $48 \mathrm{~h}$ before freeze-drying.

\subsection{Collagen Hydrogel Formation}

\subsubsection{Thermally Crosslinked Hydrogels}

Collagen solutions were prepared at twice the final desired concentration by dissolving in $20 \mathrm{mM}$ acetic acid. Final neutralized collagen solutions were prepared on ice and consisted of $500 \mu \mathrm{L}$ collagen, $390 \mu \mathrm{L}$ distilled water, $100 \mu \mathrm{L} 10 \times$ PBS and $10 \mu \mathrm{L} 1 \mathrm{M} \mathrm{NaOH}$ per $1 \mathrm{~mL}$ of neutralized collagen. $200 \mu \mathrm{L}$ of collagen was transferred per well of 48 well culture plates, and thermally cross-linked by incubation at $37^{\circ} \mathrm{C}$ for $45 \mathrm{~min}$.

\subsubsection{UV Cross-Linked Hydrogels}

Methacrylated collagen hydrogels were prepared using the same protocol with the addition of lithium phenyl-2,4,6-trimethylbenzoylphosphinate (LAP) as photo-cross-linker to a final concentration of $0.1 \%$. Methacrylated collagen was cross-linked by irradiating with an Omnicure $1000 \mathrm{UV}$ lamp at $365 \mathrm{~nm}$, at radiance of $12 \mathrm{~mW} / \mathrm{cm}^{2}$ for 12, 25, or $50 \mathrm{~s}$.

\subsection{Fourier Transform Infra-Red (FTIR) Spectroscopy}

A Shimadzu Fourier Transform Infrared Spectrophotometer IRPrestige-21 was used with a Miracle head attachment and IR Solution software. The freeze-dried foam version of collagen was used to create a homogeneous layer of material for analysis. 


\subsection{Circular Dichroism (CD)}

Samples were dissolved in $20 \mathrm{mM}$ acetic acid to a concentration of $0.3 \mathrm{mg} / \mathrm{mL}$. Samples were injected into a quartz cuvette with $1 \mathrm{~mm}$ path length in a Jasco J-810 spectropolarimeter. Ellipticity was recorded from $400 \mathrm{~nm}$ down to $190 \mathrm{~nm}$ in $1 \mathrm{~nm}$ intervals at constant temperatures (ranging from $5{ }^{\circ} \mathrm{C}$ up to $40^{\circ} \mathrm{C}$ ). Readings were taken in triplicate for each sample.

\subsection{SDS-PAGE}

Samples were dissolved in a solution of $20 \mathrm{mM}$ sodium phosphate, containing $1.0 \%$ SDS and 3.5 M urea. $\mathrm{NaOH}$ was added dropwise to achieve a neutral $\mathrm{pH}$. Samples were centrifuged for $5 \mathrm{~min}$ at $800 \times g$ to remove any undissolved particles. Samples $(30 \mu \mathrm{L})$ were transferred to Eppendorf tubes and mixed with $5 \mu \mathrm{L}$ of $6 \times$ sample buffer to give final concentrations of $62.5 \mathrm{mM}$ Tris $\mathrm{pH} 6.8,2 \% \mathrm{SDS}, 10 \%$ glycerol and $0.01 \%$ bromophenol blue. Finally samples were heated at $100{ }^{\circ} \mathrm{C}$ for $5 \mathrm{~min}$ in a dry bath incubator and loaded into Bio-Rad Mini-PROTEAN TGX Stain-Free Gels (4-20\%). $4 \mu \mathrm{L}$ of Bio-Rad Precision Plus Protein Dual Colour Standards (Bio-Rad, Gladesville, NSW, Australia) and $10 \mu \mathrm{L}$ of samples was loaded. An initial run at $60 \mathrm{~V}$ for 20 min was performed to stack all samples, then the gel was run at $120 \mathrm{~V}$ for $55 \mathrm{~min}$. Gels were stained with $0.75 \mathrm{~g} / \mathrm{L}(w / v)$ Coomassie blue R-250 (Bio-Rad, Gladesville, NSW, Australia) in 15\% (v/v) methanol and 5\% $(w / v)$ acetic acid for $30 \mathrm{~min}$ and destained with $30 \%(v / v)$ methanol and $10 \%(v / v)$ acetic acid.

\subsection{UV Rheology}

Rheological measurements were done with the TA Instruments AR-G2 Rheometer with a UV adapter, and an Omnicure series $1000365 \mathrm{~nm}$ light source. Changes in both storage and loss modulus were determined, applying a $1 \%$ strain and frequency of $1 \mathrm{~Hz}$ with and without applied UV light. Light intensities were measured using a Silver Line UV Radiometer from CON-TROL-CURE. The geometry used was a $20 \mathrm{~mm}$ parallel plate with a $200 \mu \mathrm{m}$ gap between the plate and the sample.

\subsection{D Surface Seeding of Cells}

NSC-34 cells (CELLutions, Toronto, ON, Canada) were cultured on both modified and unmodified fish collagen. Unmodified collagen coatings were prepared by coating wells of 48 -well plates with $200 \mu \mathrm{L}$ of $2.5 \%$ unmodified fish collagen. After allowing the collagen to thermally crosslink at $37^{\circ} \mathrm{C}$ for 45 min cells were seeded to all gels at a density of $2 \times 10^{3}$ cells $/ \mathrm{cm}^{2}$. Methacrylated samples containing $2.5 \%$ collagen and $0.1 \%$ LAP were cross-linked by irradiating with a $365 \mathrm{~nm}$ UV lamp for $30 \mathrm{~s}$ at $12 \mathrm{~mW} / \mathrm{cm}^{2}$ and seeded as above. Growth media consisted of a 50:50 mixture of high glucose Dulbecco's Modified Eagle's Medium (DMEM) and F12 Nutrient Mixture (F12) supplemented with 10\% $(v / v)$ fetal bovine serum (FBS, Bovogen, Interpath Services, Heidelberg West, VIC, Australia). Cells were maintained at $37{ }^{\circ} \mathrm{C}$ in a humidified $5 \% \mathrm{CO}_{2}$ environment. After $24 \mathrm{~h}$, wells under differentiation conditions were changed to media containing high glucose Dulbecco's Modified Eagle's Medium (DMEM), 2\% horse serum and $100 \mathrm{U} / \mathrm{mL}$ penicillin/streptomycin. Media changes were performed every 2 days.

RenCell VM (Merck, Bayswater, Vic, Australia) neural progenitor cells were seeded to the gels at a density of $30 \times 10^{3} / \mathrm{cm}^{2}$. After crosslinking, growth media consisting of (DMEM) with $2 \%$ B27 supplement, $10 \mathrm{ng} / \mathrm{mL}$ basic fibroblast growth factor (bFGF, Promega, Alexandria, Australia) and $20 \mathrm{ng} / \mathrm{mL}$ epidermal growth factor were added (EGF, Promega, Alexandria, Australia). Cells were maintained at $37^{\circ} \mathrm{C}$ in a humidified $5 \% \mathrm{CO}_{2}$ environment. After $24 \mathrm{~h}$, wells under differentiation conditions were changed to the same media without growth factors. Media changes were performed every 2 days.

\subsection{Cell Encapsulation}

NSC-34 cells were encapsulated at $2 \times 10^{6}$ cells $/ \mathrm{mL}$ in unmodified or methacrylated fish collagen. An allotment of cell suspension, $200 \mu \mathrm{L}$, was deposited in each well of 48 well 
plates and cross-linked at UV irradiance of $12 \mathrm{~mW} / \mathrm{cm}^{2}$ for 12,25 , or $50 \mathrm{~s}$, or by thermal crosslinking at $37^{\circ} \mathrm{C}$ for $45 \mathrm{~min}$. Hydrogels were then soaked for $10 \mathrm{~min}$ in PBS to remove residual LAP, and then changed to either growth or differentiation culture media. Cultures were maintained at $37{ }^{\circ} \mathrm{C}$ in a humidified environment with $5 \% \mathrm{CO}_{2}$. Media changes were performed every 2 days.

RenCell VM cells were encapsulated at $1 \times 10^{6}$ cells $/ \mathrm{mL}$ in unmodified fish collagen. Hydrogels were thermally cross-linked, soaked in PBS and transferred to culture media as described above. Media changes were performed every 2 days. Primary skeletal myoblasts isolated from 5 to 6 week old male mice and kindly donated by Anita Quigley (ACES, St. Vincent's Hospital Melbourne) were encapsulated and differentiated in 5\% methacrylated gelatin (GelMA, 82\% degree of functionalization), provided by the Australian National Fabrication Facility (ANFF) Materials Node, University of Wollongong, Australia). The cells were cultured in HAM's F10 media, supplemented with 20\% FBS and $2.5 \mathrm{ng} / \mathrm{mL}$ bFGF and differentiated in DMEM supplemented with $1 \%$ horse serum.

\subsection{D Bioprinting}

Coaxial printing utilised a customized printer (Figure 1) developed at the Translational Research Initiative for Cell Engineering and Printing (TRICEP, University of Wollongong, Australia). The dual syringes ink reservoirs have separate temperature control, allowing for independent temperature equilibration for each ink. The GelMA core was maintained at $16{ }^{\circ} \mathrm{C}$ while the methacrylated collagen shell was maintained at $18{ }^{\circ} \mathrm{C}$, and printed at room temperature with the pressure around 140 to $200 \mathrm{kPa}$ to ensure the formation of continuous lines [58].
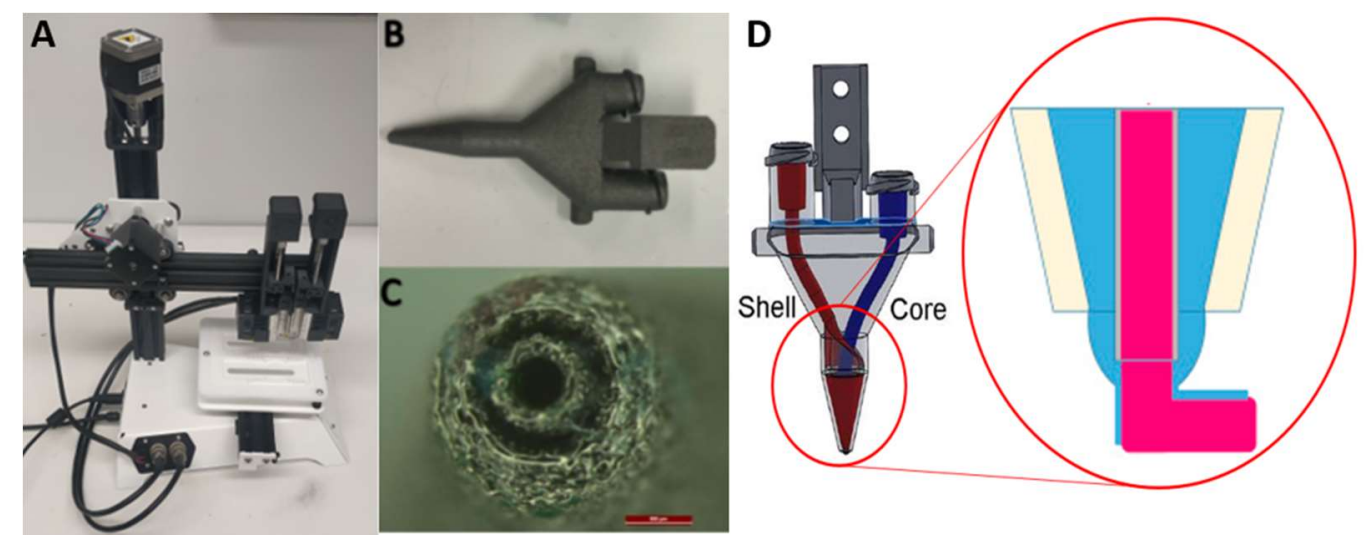

Figure 1. Custom made coaxial BioScribe 3D printer developed at TRICEP (A); 3D printer coaxial nozzle that allows for two syringes to be attached (B); Nozzle tip, comprised of an inner and outer orifice for the extrusion of the core and the shell components of the filaments, respectively. The scale bar represents $500 \mu \mathrm{m}(\mathrm{C})$; Schematic drawing showing the channels inside the nozzle, being the core (red) used to extrude the supporting GelMA, while the shell (blue) is a softer coating of NSC-34 cells encapsulated in ColMA (D).

We prepared the GelMA and neutralized fish ColMA solutions and suspended $10 \times 10^{6} / \mathrm{mL}$ primary skeletal myoblasts or $2 \times 10^{6} / \mathrm{mL}$ NSC-34 neurons in each solution, respectively. The suspensions were loaded into temperature-stabilized $3 \mathrm{~mL}$ syringes with diameters of $5 \mathrm{~mm}$ (Figure 1). The inner core was extruded at the centre of the print while the shell created a cylinder around it, producing a multi-material, concentric extrusion print. The extrusion was actuated independently by each module's piston, creating a variable printing ratio. After optimization, we compared two printing ratios: 90:10 and 95:05 (core: shell). This allowed for good support provided by the GelMA core, whilst producing an intact layer of surrounding shell. The remaining printing parameters included $x-y$ dimensions $(10 \times 10 \mathrm{~mm})$, thickness of layers $(0.6 \mathrm{~mm})$, strand to strand distance of $1.5 \mathrm{~mm}$, speed of print and flow $(100 \mathrm{~mm} / \mathrm{min}$ and $0.196 \mu \mathrm{L} / \mathrm{mm}$, respectively). Scaffolds 
were irradiated for $12 \mathrm{~s}$ at $12 \mathrm{~mW} / \mathrm{cm}^{2}(365 \mathrm{~nm})$ and cultures maintained in myoblast differentiation media for 21 days, with media changes every second day.

\subsection{Live-Dead Cell Viability Test}

Staining of viable cells with $5 \mu \mathrm{M}$ Calcein AM solution and dead cells with $1 \mu \mathrm{g} / \mathrm{mL}$ propidium iodide (PI) was used to assess the effect of encapsulation and UV treatment on cells. Viable cells take up Calcein and fluoresce bright green, whereas dead cells take up propidium iodide and fluoresce bright red. Cells were imaged using a Zeiss Axiovert 40 CFL inverted fluorescence and phase contrast microscope equipped with AxioVision software (SE64 Rel. 4.9.1, Zeiss Australia, North Ryde NSW, Australia).

\subsection{Immunocytochemistry}

For immunocytochemistry, 2D samples were fixed with 3.7\% $(w / v)$ paraformaldehyde (PFA) in phosphate-buffered saline (PBS) for $10 \mathrm{~min}$ at RT and subsequently blocked and permeabilized with $0.3 \%(v / v)$ Triton-X-100/10\% $(v / v)$ donkey serum (DS) in PBS for $1 \mathrm{~h}$ at RT. Alternatively, 2D samples were fixed and permeabilized with acetone/methanol (50:50) for $10 \mathrm{~min}$ on ice. In this case, blocking was achieved with $10 \%(v / v)$ DS/0.1\% $(v / v)$ Tween 20 in PBS for $1 \mathrm{~h}$ at RT. All samples were washed three times for $5 \mathrm{~min}$ in PBS. Samples were incubated overnight at $4{ }^{\circ} \mathrm{C}$ with primary antibodies diluted in $10 \%(v / v)$ DS in PBS. Primary antibodies were mouse (1:1000, Abcam, Melbourne, VIC, Australia) or chicken (1:1000, Merck-Millipore, Bayswater VIC, Australia), anti- $\beta$-III-tubulin, mouse anti-desmin (1:200, Novocastra- Leica biosystems, Mt Waverley, VIC, Australia), mouse antisarcomeric alpha actinin (1:200, Abcam, Melbourne, VIC, Australia). After incubation with the primary antibodies, samples were washed three times for $5 \mathrm{~min}$ with $0.1 \%(v / v)$ TritonX-100 in PBS. AlexaFluor 594 conjugated donkey anti-mouse, AlexaFluor 488 conjugated goat anti-chicken and AlexaFluor 555 conjugated goat anti-mouse secondary antibodies (Thermofisher, North Ryde, NSW, Australia) were incubated for $1 \mathrm{~h}$ at 1:1000 dilution in $10 \%(v / v)$ DS in PBS at RT. AlexaFluor 555 conjugated bungarotoxin (1:500, Thermofisher, North Ryde, NSW, Australia) was also added to relevant samples at this step. $1 \mu \mathrm{g} / \mathrm{mL}$ of 4',6-diamidino-2-phenylindole (DAPI, Thermofisher, North Ryde, NSW, Australia) in PBS was added for $5 \mathrm{~min}$, followed by $3 \times 5 \mathrm{~min}$ washes in PBS. Times for all steps were doubled for encapsulated cells in 3D samples, except for primary antibody incubations which were incubated overnight. A Zeiss Axiovert 40 CFL inverted fluorescence microscope equipped with AxioVision software was used for imaging. Immunostained bioprinted scaffolds were also imaged using a Leica TSC SP5 II confocal microscope equipped with LAS AF software (Leica Microsystems, Macquarie Park, NSW, Australia).

\section{Results}

Following the extraction, purification and freeze-drying procedures a translucent powder was obtained with a yield of $7 \%$ of the original dissolved and freeze-dried protein mixture. This purified product was subjected to the characterization studies described below.

\subsection{FTIR Spectroscopy}

FTIR spectra for bovine and marine collagen as well as denatured collagen (gelatin) were obtained (Figure 2). The absorbance at $1620-1670 \mathrm{~cm}^{-1}$ (amide I) associated with the stretching of the carbonyl groups ( $\mathrm{C}=\mathrm{O}$ bond), along the polypeptide backbone [59] and is a sensitive marker of the secondary structure of proteins [60]. The peaks observed at around $1700 \mathrm{~cm}^{-1}$ are normally attributed to collagen's $\beta$-sheet structure, which is close to the theoretical point of random coil formation, usually assigned at around $1645 \mathrm{~cm}^{-1}$ [61,62]. Moreover, the amide III band at around $1238 \mathrm{~cm}^{-1}$ can also be seen, because of the NH bend, coupled with the $\mathrm{CN}$ stretch. Finally, the presence of both amide I and amide III bands indicates that the helical structure of collagen is intact. 


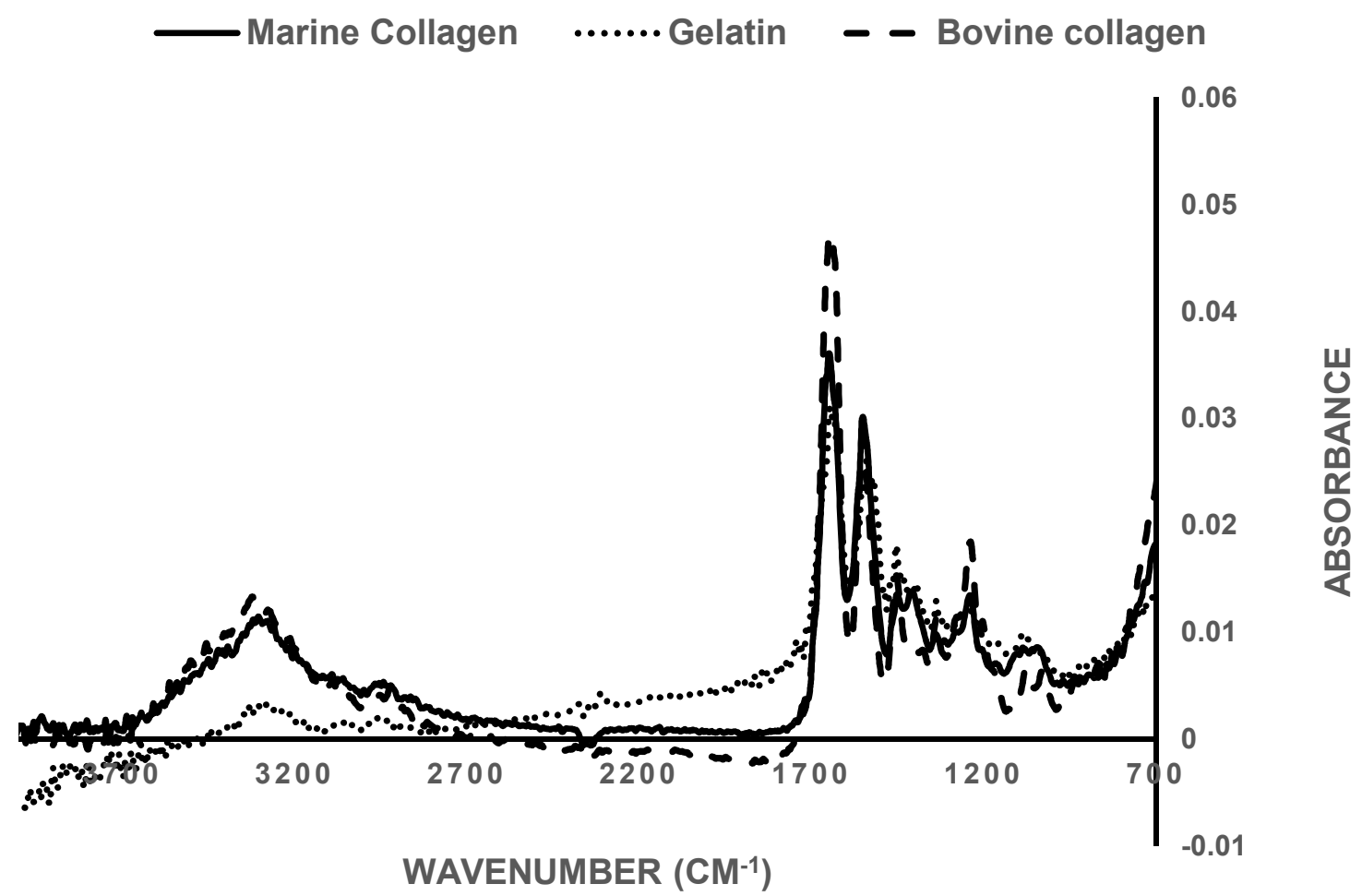

Figure 2. Comparison of FTIR spectra of extracted marine-derived collagen (solid line), commercially available bovine collagen (dashed line) and commercial gelatin (dotted line). Samples were tested as freeze-dried foams at RT.

This was further assessed by comparison of the absorbance ratio between bands at 1235 and $1450 \mathrm{~cm}^{-1}$. It has been previously reported that the absorbance ratio $\mathrm{I}_{1235} / \mathrm{I}_{1450}$ of pure collagen is around 1 [63]. In the case of the bovine collagen used here the ratio was 1.04, while for marine-derived collagen the ratio was 1.02. Methacrylation of the marine collagen did not affect the FTIR spectra (Figure S1) and the ratio of absorbance bands at 1235 and $1450 \mathrm{~cm}^{-1}$ was maintained at 1.05 .

When collagen is denatured it loses the triple helical structure, converting to gelatin. Gelatin has a $\mathrm{I}_{1235} / \mathrm{I}_{1450} \mathrm{~cm}^{-1}$ ratio of $\approx 0.69[63]$, a $\mathrm{I}_{1235} / \mathrm{I}_{1450} \mathrm{~cm}^{-1}$ ratio of 0.67 , in comparison with that of the extracted marine sample (1.02). This further supports the integrity of the collagen type I obtained from the extraction and purification protocol for the fish skin.

\subsection{Circular Dichroism}

The triple helical structure of collagen results in a CD spectrum with a rotatory maximum at $221 \mathrm{~nm}$, a minimum close to $205 \mathrm{~nm}$, and a consistent crossover point at around $212 \mathrm{~nm}[64,65]$. The CD spectra for the marine collagen, the methacrylated marine collagen compared to commercial bovine collagen and gelatin, are presented in Figure 3. The rotatory maximum and minimum point results are displayed in Table 1. The experimental results for both commercially available bovine collagen and the extracted marine collagen were close to the theoretical values and were unaffected by methacrylation of the marine collagen. Gelatin due to the loss of the triple helix lacks the rotatory profile. 


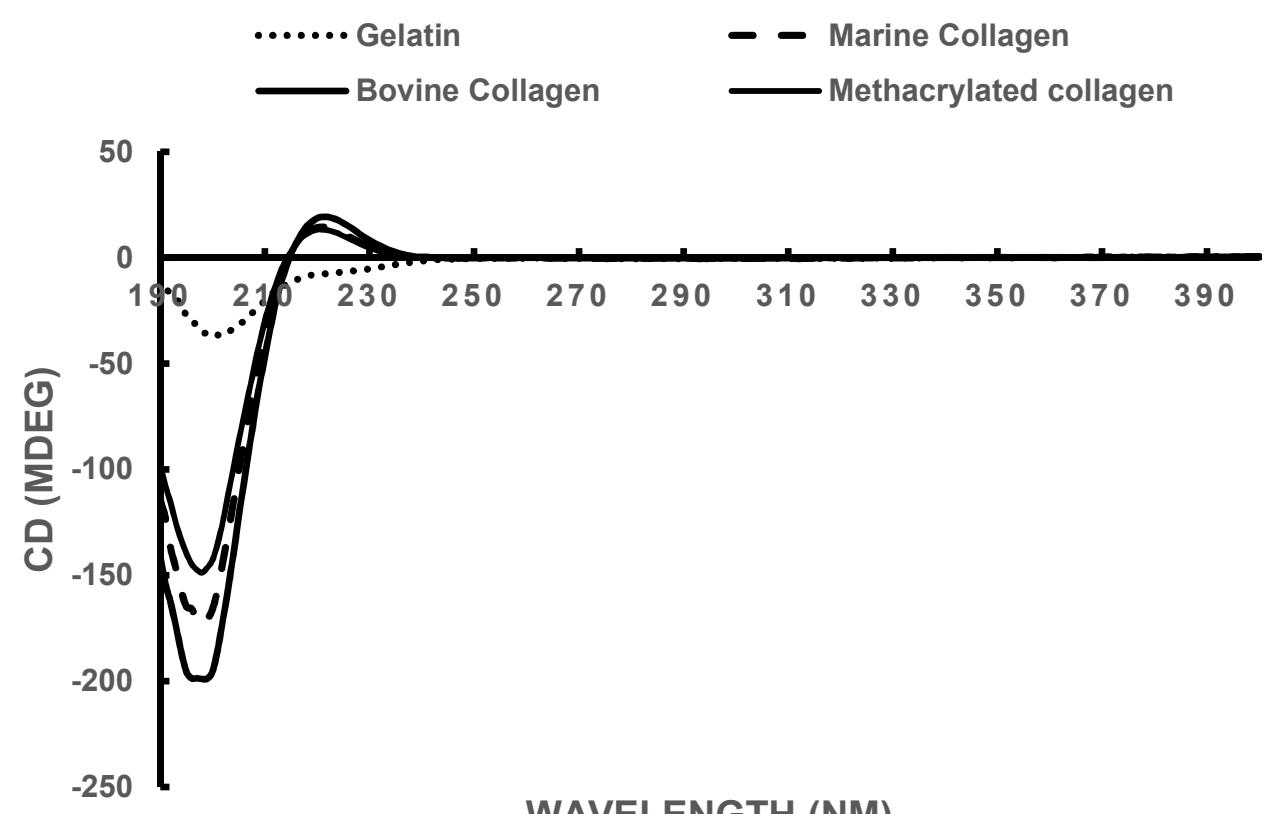

Figure 3. Circular dichroism spectra, taken at $5{ }^{\circ} \mathrm{C}$. All samples were dissolved in $20 \mathrm{mM}$ acetic acid and diluted to a final concentration of $0.3 \mathrm{mg} / \mathrm{mL}$.

Table 1. CD data for the extracted marine collagen, compared with commercial bovine collagen and gelatin. The theoretical values are also listed.

\begin{tabular}{lccc}
\hline Sample & $\begin{array}{c}\text { Rotatory Minimum } \\
(\mathbf{n m})\end{array}$ & $\begin{array}{c}\text { Rotatory Maximum } \\
\text { (nm) }\end{array}$ & $\begin{array}{c}\text { Crossover Point } \\
\text { (nm) }\end{array}$ \\
\hline Bovine Collagen & 198 & 222 & 215 \\
Marine Collagen & 198 & 220 & 214 \\
Methacrylated Marine & 198 & 220 & 214 \\
Collagen & 199 & - & - \\
Gelatin & 205 & 221 & 212 \\
Theoretical Collagen [64] & & & \\
\hline
\end{tabular}

\subsection{SDS-PAGE Electrophoresis}

SDS-PAGE electrophoresis was used to assess the purity of the extracted collagen. Collagen type I has a unique set of chains comprising its helical structure, each with its own specific molecular weight. The $\alpha$-region comprising the two $\alpha$-1 chains of the bovine collagen and the two batches of our extracted fish collagen is around $140 \mathrm{kDa}$ (Figure 4). Moreover, the $\beta$-region shows the heavier $\alpha 2$ chain at around $250 \mathrm{kDa}$. Finally a $\gamma$-region is observed above the $250 \mathrm{kDa}$ mark in both cases. This corresponds to the reported patterns for collagen type I found in the literature [66], where the $\alpha$-region is localized between 100 and $150 \mathrm{kDa}$, while the $\beta$-region is close to $250 \mathrm{kDa}$ and the $\gamma$-region at around $300 \mathrm{kDa}$. The denaturation of collagen into gelatin results in a blurred band, in which no distinctive regions are observed. The lack of any major blurring and the clarity of the component bands of our extracted fish collagen suggested that the purity of the extracted material was comparable to the commercially available bovine collagen. The clarity of bands in the methacrylated collagen sample confirms that no denaturation of the marine collagen occurred during the process of methacrylation. 


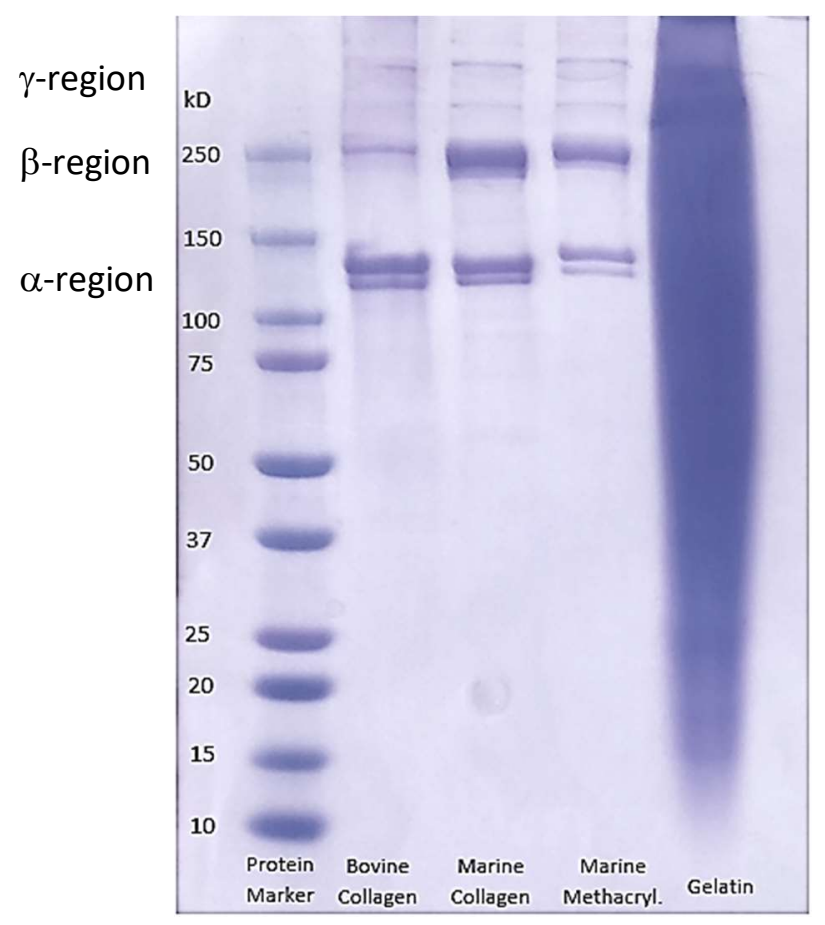

Figure 4. SDS-PAGE of commercially available bovine collagen and gelatin, compared with our extracted marine collagen, before and after methacyrylation.

\subsection{Rheology}

The storage modulus of methacrylated marine collagen at 2.5 and $1 \mathrm{mg} / \mathrm{mL}$ was tested during exposure to $12 \mathrm{~mW} / \mathrm{cm}^{2} \mathrm{UV}$ intensity for $12 \mathrm{~s}$ (Figure 5). Upon exposure to UV light the collagen gelled and an increase in storage modulus to $250 \mathrm{~Pa}(2.5 \mathrm{mg} / \mathrm{mL})$ and $20 \mathrm{~Pa}(1 \mathrm{mg} / \mathrm{mL})$ in less than $12 \mathrm{~s}$ was observed. Rapid crosslinking and gelation is critical for successful printing of this material.

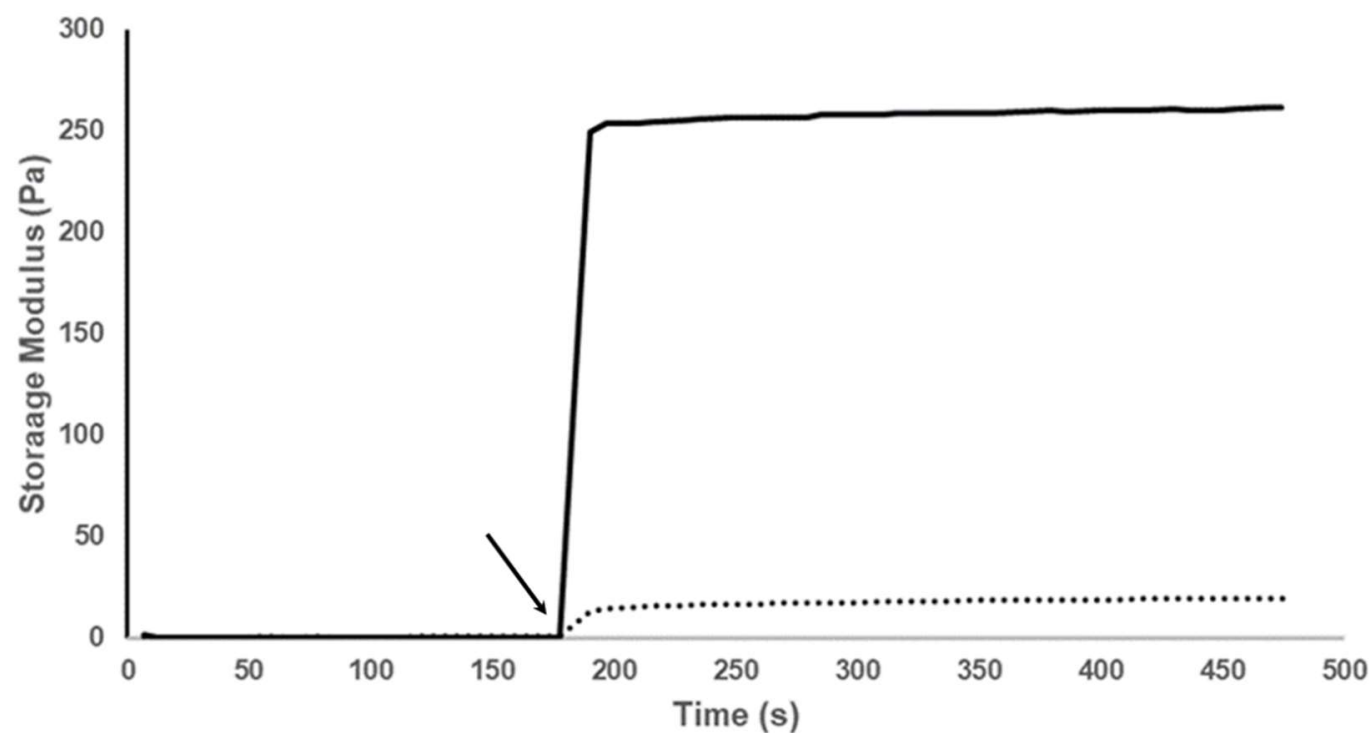

Figure 5. Storage moduli of both $2.5 \mathrm{mg} / \mathrm{mL}$ and $1 \mathrm{mg} / \mathrm{mL}$ methacrylated collagen in the presence of $0.1 \%$ LAP cross-linker. The arrow indicates the point at which the UV light was switched on. The samples were irradiated at $12 \mathrm{~mW} / \mathrm{cm}^{2}$ for $12 \mathrm{~s}$. 


\subsection{Compatibility of Neural Cells with Marine Collagen}

Collagen solutions were prepared and were either thermally or UV-crosslinked, as described in the Materials and Methods section. NSC-34 cells were seeded onto the collagen gels and cultured in growth media for 7 days, resulting in an increase in cell density. Those cultured in differentiation media showed morphological signs of differentiation by day 7 (Figure 6), i.e., the cells were flattened and elongated with short processes. NSC-34 cells encapsulated in fish collagen (Figure 7) failed to develop this differentiated morphology over a 14 day time period, but continued to proliferate.

In both surface seeded and encapsulated cell experiments, ReNcell VM neural progenitor cells proliferated and induced contraction of the collagen gels over 7 days $(60 \%$ contraction). This effect increased with cell density, as evidenced by the increased contraction with time as cells increased in number, as well as the contraction that was observed at early time points when cells were initially seeded at higher densities (e.g., cells encapsulated at $10 \times 10^{6}$ cells $/ \mathrm{mL}$ contracted the gels overnight, while at lower densities $\left(2 \times 10^{6}\right.$ cells $/ \mathrm{mL}-5 \times 10^{6}$ cells $\left./ \mathrm{mL}\right)$ contraction of the gels to one third of their original size occurred over a 7 day period. Encapsulation of cells at $1 \times 10^{6}$ cells $/ \mathrm{mL}$ allowed for long term culture (up to 21 days) without significant contraction of the gels. Cells cultured in differentiation media (both surface seeded and encapsulated) formed extensive branching neurite networks by 7 days (Figures 6 and 8), indicative of differentiation.

\subsection{Live and Dead Staining}

When cells were surface seeded on marine collagen, live and dead staining at 1 and 7 days showed good cell survival for both NSC-34 and ReNcell VM cells in both growth and differentiation media with very few dead cells (Figure 6). The increase in cell number by 7 days in proliferation media was evident, as was the contraction of collagen gels with increasing densities of ReNcell VM cells. ReNcell VM cells in differentiation media formed interconnected neural rosettes by 7 days in 2D culture (Figure 6E,G).
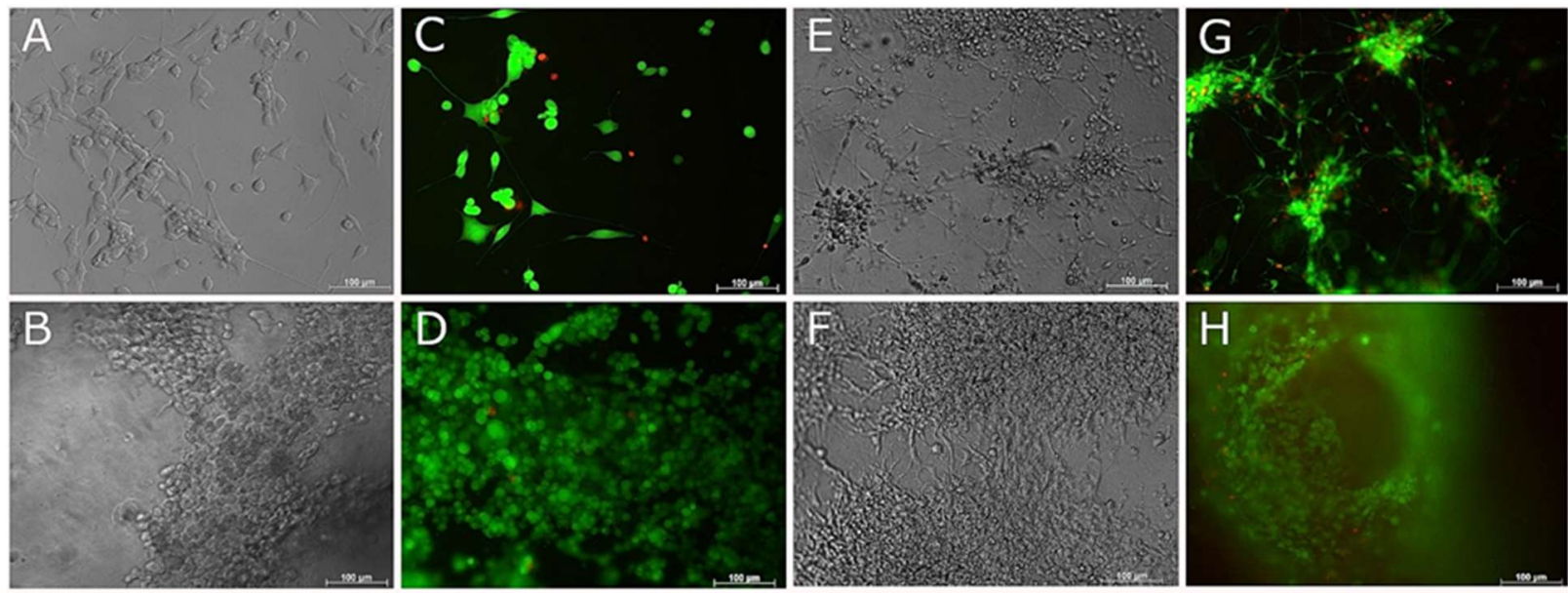

Figure 6. Live and Dead and phase contrast images of NSC-34 and RenCell VM neural progenitor cells surface seeded to 2.5/mL fish collagen. Phase contrast $(\mathbf{A}, \mathbf{B}, \mathbf{E}, \mathbf{F})$ and live and dead $(\mathbf{C}, \mathbf{D}, \mathbf{G}, \mathbf{H})$ images taken of NSC-34 (A-D) and RenCell VM (E-H) at day 7. Top and bottom rows correspond to cells cultured with differentiation media and growth media, respectively. Scale bars represent $100 \mu \mathrm{m}$.

Encapsulated cells in 3D culture, showed good cell survival for both NSC-34 and ReNcell VM cell types by 1 day and 7 days (Figures 7 and 8 ) in both growth and differentiation media, however by 14 days, cell survival declined significantly. 

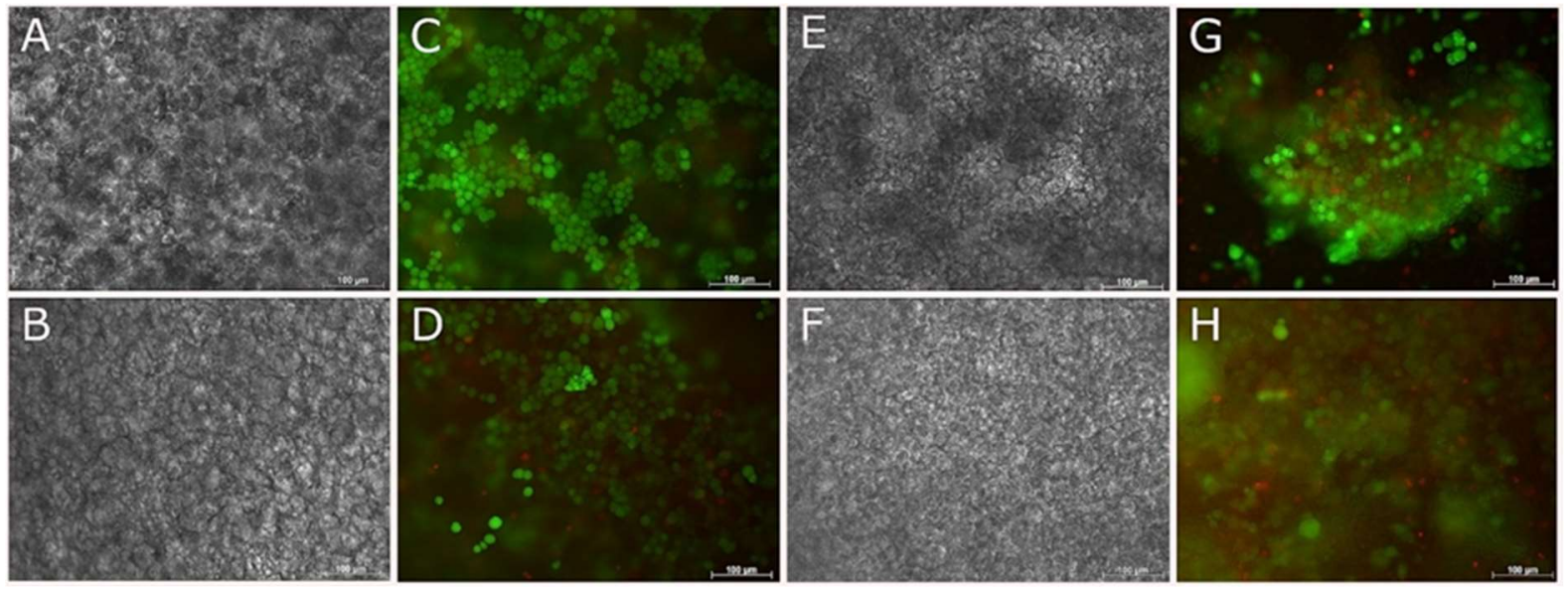

Figure 7. Live and Dead and phase contrast images of NSC-34 cells encapsulated in $2.5 / \mathrm{mL}$ fish collagen. Phase contrast $(\mathbf{A}, \mathbf{B}, \mathbf{E}, \mathbf{F})$ and live and dead $(\mathbf{C}, \mathbf{D}, \mathbf{G}, \mathbf{H})$ images taken of NSC-34 at 7 (A-D) and 14 (E-H) days. Top and bottom rows correspond to cells cultured with differentiation media and growth media, respectively. Scale bars represent $100 \mu \mathrm{m}$.
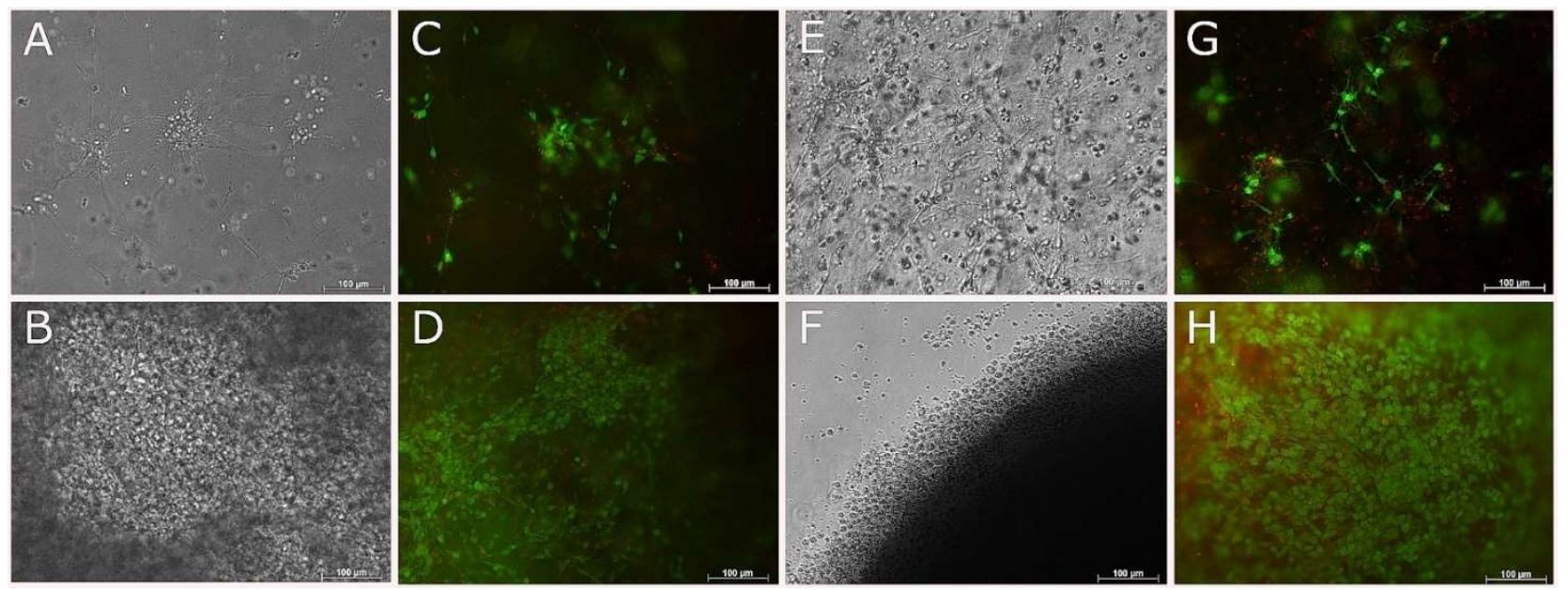

Figure 8. Live and Dead images of RenCell VM neural progenitor cells encapsulated in $2.5 / \mathrm{mL}$ fish collagen. Phase contrast $(\mathbf{A}, \mathbf{B}, \mathbf{E}, \mathbf{F})$ and live and dead $(\mathbf{C}, \mathbf{D}, \mathbf{G}, \mathbf{H})$ images taken of RenCell VM at 7 (A-D) and 14 (E-H) days. Top and bottom rows correspond to cells cultured with differentiation media and growth media, respectively. Scale bars represent $100 \mu \mathrm{m}$.

\subsection{Compatibility of NSC-34 with UV-Cross-Linked Methacrylated Fish Collagen}

The ability to produce UV-crosslinkable fish collagen paves the way for printing collagen based complex constructs. The NSC-34 cell line was selected to evaluate the cytocompatibility of the UV crosslinking process. The optimal UV-crosslinking condition was found to be $12 \mathrm{~s}$ at $12 \mathrm{~mW} / \mathrm{cm}^{2}$. Longer cross-linking times, or higher irradiances in extrusion printed scaffolds was found to decrease cell viability by $24 \mathrm{~h}$. NSC-34 cells were seeded to the surface of, and encapsulated in, UV-cross-linked methacrylated fish collagen gels and cultured for either 7 days (surface-seeded) or 21 days (encapsulated) in either growth media or differentiation media (Figure 9). Live and dead staining showed that cell viability was high and the cells continued to proliferate when surface seeded (by 7 days) or encapsulated (by 21 days). 

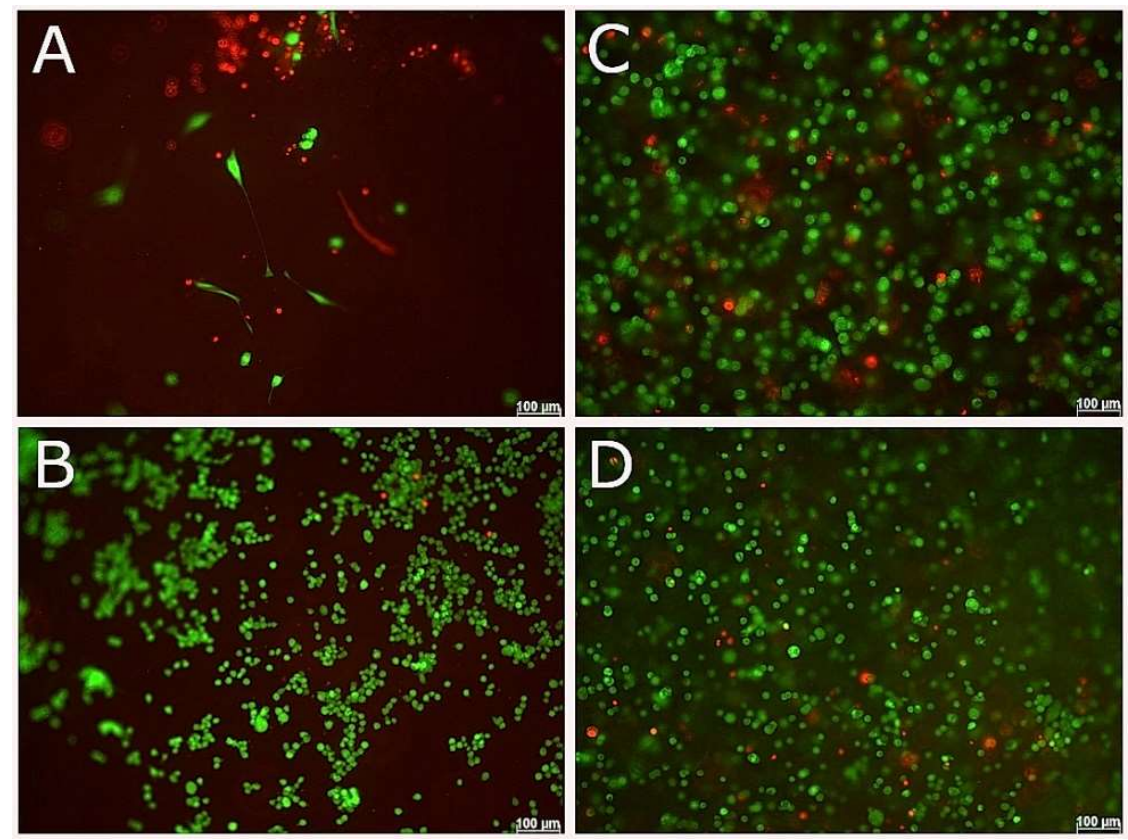

Figure 9. Live and Dead images of NSC-34 cells encapsulated in or surface seeded to $2.5 / \mathrm{mL}$ fish collagen UV crosslinked for $12 \mathrm{~s}$ at $12 \mathrm{~mW} / \mathrm{cm}^{2}$. Live and dead images taken of NSC-34 surface seeded to methacrylated fish collagen at day $7(\mathbf{A}, \mathbf{B})$ and encapsulated in methacrylated fish collagen at day $21(\mathbf{C}, \mathbf{D})$. Top and bottom rows correspond to cells cultured with differentiation media and growth media, respectively. Scale bars represent $100 \mu \mathrm{m}$.

\subsection{D Coaxial Printing of Primary Myoblasts and NSC-34 Motor Neuron Cell Line}

The neuromuscular junction was used as an example in this study to demonstrate the potential of building multiple cell type containing constructs, which is difficult to achieve via conventional 2D cell culture systems. Primary myoblasts and NSC-34 cells were successfully differentiated in $2 \mathrm{D}$, both separately and in co-culture prior to setting up coaxial printing of skeletal myoblasts and neural cells.

The optimum seeding density for 2D differentiation of NSC-34 cells was $2 \times 10^{3}$ cells $/ \mathrm{cm}^{2}$ whereas for skeletal myoblasts, which require a much higher $2 \mathrm{D}$ density for myoblast fusion, the optimum seeding density was $30 \times 10^{3}$ cells $/ \mathrm{cm}^{2}$. A range of differentiation media were tested against both cell types, with DMEM media supplemented with $1 \%$ horse serum and $1 \% \mathrm{P} / \mathrm{S}$ being chosen for co-cultures, based on the high degree of differentiation for both skeletal muscle and motor neuron cells in this media. For 2D co-culture, skeletal myoblasts were cultured at a density of $30 \times 10^{3}$ cells $/ \mathrm{cm}^{2}$ and differentiated for 3 days before seeding NSC-34 cells at a density of $2 \times 10^{3}$ cells $/ \mathrm{cm}^{2}$ and maintaining in the same media for 3-4 further days with media changes every 2 days.

Skeletal muscle cells and motor neuron cells were separately encapsulated in a range of marine collagen, and ColMA concentrations and in different GelMA formulations in terms of polymer concentration and degree of functionalization (DoF). The duration of cross-linking and UV irradiance were optimized in terms of resulting cell viability and 3D differentiation of the cells. The aim was to determine the conditions that were the most suitable to support motor neuron and muscle cell survival and differentiation separately, in 3D environments before proceeding to 3D bioprinting. Skeletal muscle differentiation in 3D was optimal at $10 \times 10^{6}$ myoblasts/mL suspended in 5\% $(w / v)$ GelMA $(82 \%$ DoF) and cross-linked with $0.1 \%$ LAP. Short cross-linking times, i.e., 12 or $25 \mathrm{~s}$ at an irradiance of $12 \mathrm{~mW} / \mathrm{cm}^{2}$, resulted in high cell viabilities, as confirmed by live and dead staining at days 1, 7, and 14 after encapsulation and cross-linking. By 14 days in differentiation media, myofibers were spontaneously contracting in gels cross-linked for both 12 and $25 \mathrm{~s}$, however, myotubes more homogeneously distributed in hydrogels crosslinked for $12 \mathrm{~s}$. 
Achieving optimal conditions for differentiation of NSC-34 cells, both surface seeded and encapsulated in GelMA at a range of seeding densities, cross-linking conditions and degrees of functionalization was problematic in that cells continued to proliferate both in 2D and 3D. Differentiation was achieved on the surface of both methacrylated, and unmodified fish collagen using a range of cross-linking conditions. Live and dead staining performed at days 1 and 7 confirmed high cell viability $\beta$-III tubulin immunostainings were performed at day 7 to prove positivity for this neuronal marker. Due to the higher viability of encapsulated NSC-34 cells in methacrylated gels that were cross-linked for shorter periods of time, cross-linking of $2.5 \mathrm{mg} / \mathrm{mL}$ collagen gels for $12 \mathrm{~s}$ at $12 \mathrm{mWcm}{ }^{2}$ with cells at $2 \times 10^{6} / \mathrm{m}$, were utilised for subsequent $3 \mathrm{D}$ co-axial bioprinting.

Prior to bioprinting different printing parameters including pressure and speed of print, flow rate, temperature of the gels and receiving plates were tested to find optimum conditions to print $10 \times 10 \mathrm{~mm}$ scaffolds of 3 layers in height. The duration of cross-linking at irradiance of $12 \mathrm{~mW} / \mathrm{cm}^{2}$ needed to retain the integrity of scaffolds and retain cell viability at days 0,7 , and 14 after printing was determined to be $12 \mathrm{~s}$. Immunostaining of skeletal muscle cells in gels cross-linked for $12 \mathrm{~s}$ after 14 days in culture using anti- $\alpha-$ sarcomeric actinin, confirmed that myoblasts had fused, forming multinucleated myofibers.

Once the optimized parameters for printing of both cell types had been achieved, the separate GelMA-laden and collagen-laden syringes were transferred to the nozzle (Figure 1) and the temperature of each module was adjusted for each bioink and allowed to stabilize for $15 \mathrm{~min}$. The core module temperature was set to $16^{\circ} \mathrm{C}$ to allow GelMA solution transition to a gel state and the shell module temperature was set to $18{ }^{\circ} \mathrm{C}$. Single layer scaffolds were extruded at a flow rate of $0.196 \mu \mathrm{L} / \mathrm{mm}$ and a speed of $100 \mathrm{~mm} / \mathrm{min}$. Dimensions of the printed scaffolds were $10 \mathrm{~mm} \times 10 \mathrm{~mm} \times 0.6 \mathrm{~mm}(1.5 \mathrm{~mm}$ strandto-strand distance). The GelMA core contained a high density $\left(10 \times 10^{6}\right.$ cells $\left./ \mathrm{mL}\right)$ of skeletal muscle cells, whereas the outer shell contained the NSC-34 motor neuron cell line at $2 \times 10^{6}$ cells $/ \mathrm{mL}$ in $2.5 \mathrm{mg} / \mathrm{mL}$ methacrylated fish collagen at 2 different ratios 95 (core):5 (shell) and 90:10. Both gels were cross-linked at the same time using UV light for $12 \mathrm{~s}$ at $12 \mathrm{~mW} / \mathrm{cm}^{2}$. The scaffolds were incubated in skeletal muscle differentiation media which had been previously shown to support the highest percentages of differentiated myofibers and motor neuron-like cells.

Within the coaxially-printed scaffolds the viability of both cell types was high for up to 21 days and both cell types were observed to differentiate, as evidenced by live and dead cell staining (Figure 10). Skeletal muscle cells were differentiating by 7 days in $3 \mathrm{D}$ culture and had formed thick, contracting myofibers that aligned with the direction of printing of the scaffolds by 14 days in culture. Live and dead imaging suggested the differentiation of both cells types in the scaffolds due to differences in morphology of both cell types. Neurite outgrowth and branching was observed, indicating neural differentiation in the 3D coaxial co-culture. Immunocytochemistry of the scaffolds after 21 days in culture (Figure 11), followed by confocal imaging confirmed the location of motor neurons in the shell component and myoblasts in the core component of the bioprinted structures as well as the differentiation of each cell type. Skeletal muscle cells were immunostained with the skeletal muscle protein $\alpha$-sarcomeric actinin, while differentiated NSC-34 motor neuron cells were immunostained for $\beta$-III tubulin and neuro-muscular junctions were visualized using bungarotoxin staining. Myoblast differentiation into aligned myotubes was confirmed by $\alpha$-sarcomeric actinin positivity (Figure 11B) and anti$\beta$-III-tubulin showed that motor neuron-like cells were clustered and were in a different plane to the differentiated myotubes (Figure 11C). The presence of nodular $\alpha$-bungarotoxin staining along myofibers in close proximity to motor neuron-like cells suggested that neuro-muscular junctions had formed by 21 days, however the presence of functioning neuromuscular junctions (NMJ) requires confirmation by electro-physiological studies. 

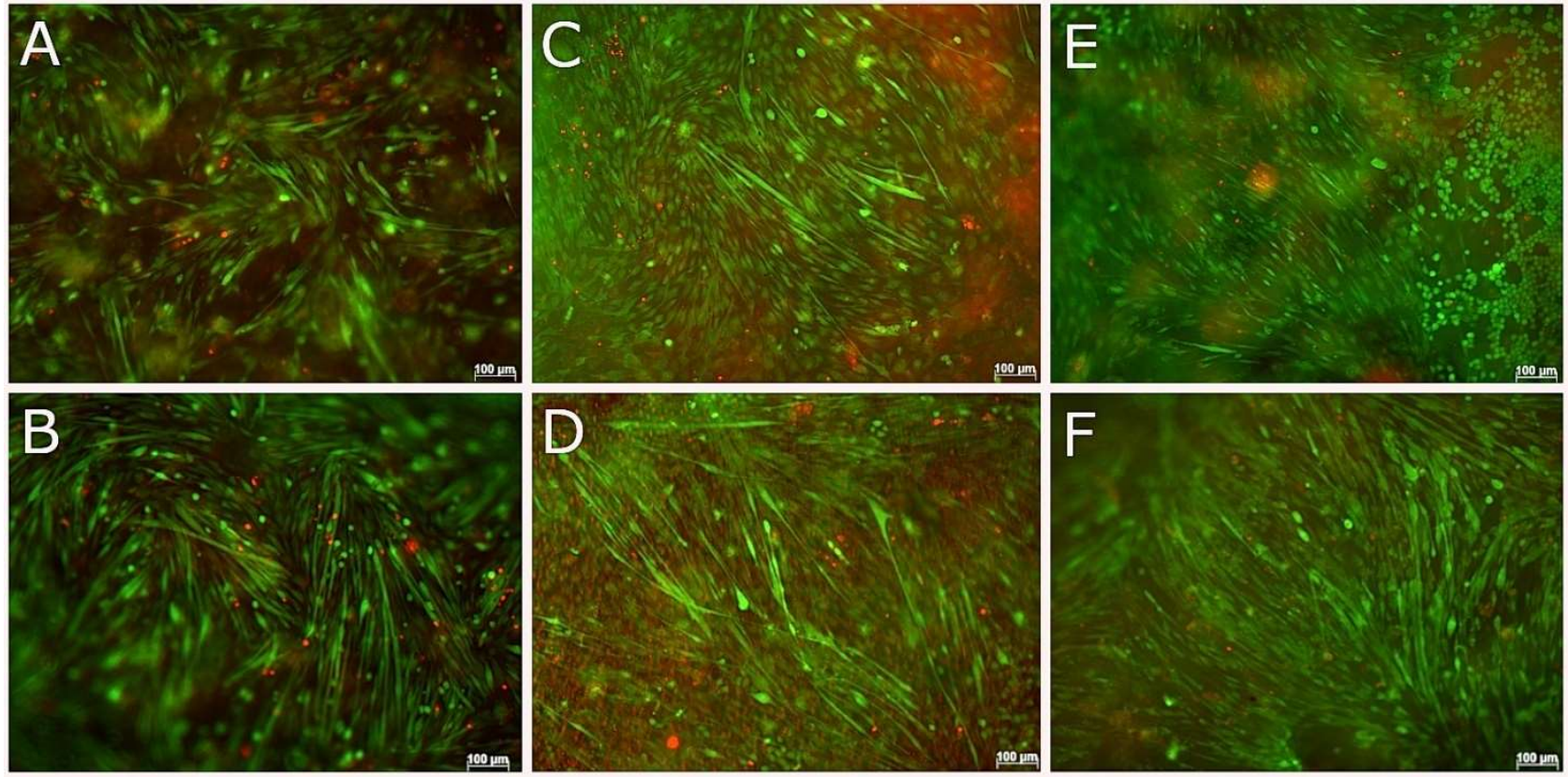

Figure 10. Live and Dead stained cells in coaxially printed scaffolds irradiated for $12 \mathrm{~s}$ at $12 \mathrm{~mW} / \mathrm{cm}^{2}$. NSC-34-laded collagen was extruded as the shell component and myoblast-laden GelMA was extruded as the core component of the bioprinted strands. Two ratios were used for extrusion, $95 \%$ core ( $5 \%$ GelMA) $/ 5 \%$ shell $(2.5 \mathrm{mg} / \mathrm{mL}$ methacrylated collagen) (A,C,E) and $90 \%$ core $(5 \%$ GelMA) $/ 10 \%$ shell $(2.5 \mathrm{mg} / \mathrm{mL}$ methacrylated collagen) $(\mathbf{B}, \mathbf{D}, \mathbf{F})$ at days 7 (A,B), 14 (C,D), and 21 (E,F). Scale bars represent $100 \mu \mathrm{m}$.

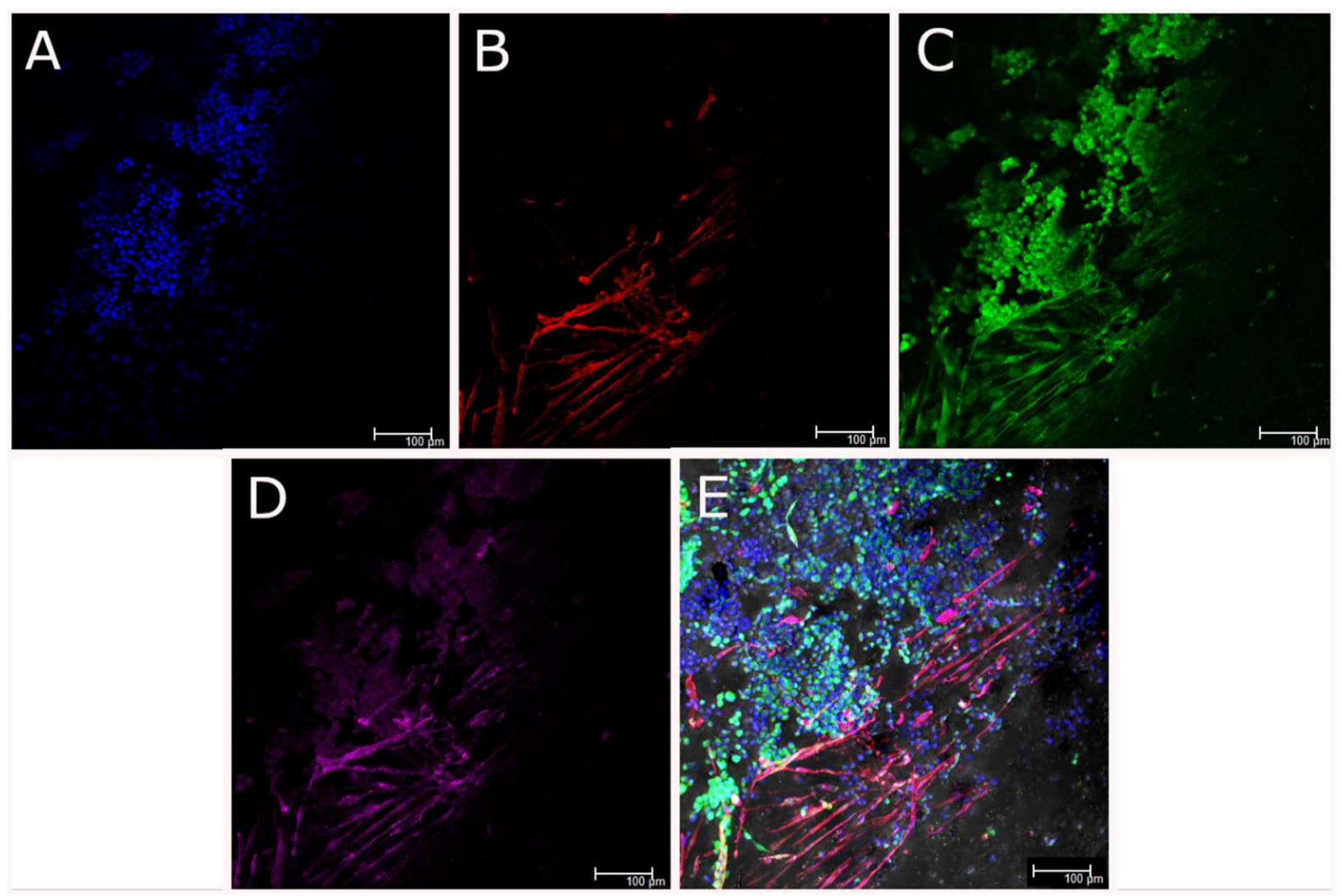

Figure 11. Coaxially-printed skeletal muscle and motor neuron cells, fixed and immunostained for nuclei (DAPI, blue, A), $\alpha$-sarcomeric actinin (red, B), $\beta$ III tubulin (green, C) and neuromuscular junctions ( $\alpha$-bungarotoxin, magenta, D). Image E is an overlay of $\mathbf{A}, \mathbf{B}, \mathbf{C}$ and D E. Scale bars represent $100 \mu \mathrm{m}$. 


\section{Discussion}

There is an absence of a reliable in vitro NMJ model to study NMJ physiology and pathogenesis, as well as to provide a platform to study NMJ disease treatments and for drug screening. Bioprinting technology offers the opportunity to fabricate in vitro tissue models by precisely positioning biomaterials and cells to create relevant tissue models for drug screening and disease modelling [67]. This in vitro model has wide applications in clinical research such as in the development of personalised therapies for neurodegenerative diseases including amyotrophic lateral sclerosis (ALS) [68], investigations into the role of the synaptogenesis in neural degeneration [69], and as a drug testing platform. In this work, skeletal myoblasts and motor neuron cells were co-axially bioprinted to form a structured NMJ model in vitro. A bioink containing fish collagen with motor neuron cells was extruded as the shell and a bioink composed of myoblast-laden gelatin methacryloyl (GelMA) solution was extruded as the core component of bioprinted hydrogel strands. Considering that myoblasts and motor neurons are surrounded by different microenvironments in situ, this specific organization was used to support the adjustment of each bioink to each particular embedded cell type while combining them into a single organized structure. It was hypothesized that the motor neuron cells would extend neurites from the shell layer towards the periphery of the core layer, where skeletal myoblasts had been shown to localize [70], establishing motor neuron-skeletal muscle contacts and forming NMJs. This was confirmed by immunostaining and confocal microscopy of the printed construct, which also revealed the alignment of sarcomeric-actinin expressing myofibers, in agreement with the alignment and enhanced differentiation of skeletal muscle myofibers in 3D extrusion printed constructs that has been reported previously [71].

We have demonstrated the capacity of marine collagen extracted from Red Snapper fish skin to support neural cell survival and differentiation. While so far limited, some preliminary work has previously been done, showing improved neural cell culture conditions in collagen composites. Schuh, C.M., et al. for example, engineered neural tissue from collagen-fibrin composites which supported Schwann cells and promoted neurite outgrowth in vitro [72]. Further work needs to be done to investigate the use of marine collagen composites for 3D neural cell culture, opening the way to progress to the incorporation of marine collagen in more complex encapsulation systems. Marine-based collagens offer an attractive alternative to commonly used terrestrial animal based material, however, as a natural product from animals, batch-to-batch variation is unavoidable. Genetically engineered collagen may provide an alternative that overcomes this limitation [73]. Ideal biomaterials should mimic the properties of natural tissue. The ECM of the brain contains a high proportion of glycosaminoglycans and a smaller fraction of collagen and other fibrous proteins compared to other tissues [74]. Given this, collagen composites incorporating marine collagen with other materials, are likely to provide more suitable environments for neuronal modelling.

It is clear that modifications need to be made to improve the physical characteristics of fish collagen hydrogels in order to improve the printability of the scaffolds. We improved the mechanical properties of the fish collagen via methacrylation and UV cross-linking, allowing for 3D bioprinting of neural cell-laden gels alone, and as coaxial scaffolds mimicking physiological systems by bringing differentiating motor neuron-like cells into close proximity with differentiating skeletal myoblasts, contained within a different material (GelMA) that had been optimized to allow skeletal myofiber formation. The increased differentiation of motor neuron-like cells in proximity to skeletal myofibers in the coaxial scaffolds has parallels in developmental biology where the presence of skeletal myoblasts is known to enhance the development of neuro-muscular junctions [75,76].

In addition to its composition, the mechanical properties of a biomaterial influences cell proliferation, survival, migration and differentiation [77]. Biomaterials for neural cell culture should aim to mimic the stiffness of natural brain tissue, which is relatively low, ranging from approximately 100 to $1500 \mathrm{~Pa}$. Our methacrylated fish collagen fell within this range, with a storage modulus of $250 \mathrm{~Pa}$ for the $2.5 \mathrm{mg} / \mathrm{mL}$ gel under our 
cross-linking conditions, and parallels the work of Iwashita et al. 2009, who produced gels derived from Tilapia fish collagen which they chemically cross-linked with 1-ethyl-3-(3dimethylaminopropyl)-carbodiimide and $\mathrm{N}$-hydroxysuccinimide in order to mimic brain tissue stiffness [54].

In this study the feasibility of co-axially bioprinting a NSC-34 motor neuron-laden collagen bioink and a skeletal myoblast-laden GelMA bioink to form a structured NMJ model in vitro was demonstrated. Co-axially bioprinting motor neuron-like cells and skeletal myoblasts in different bioinks allowed us to tune conditions for the differentiation of each cell type separately, while combining them into a structure that more closely captured the in vivo scenario in which the different cell types are encapsulated in different microenvironments. Overall, the results of this study show great potential for a novel NMJ in vitro 3D bioprinted model that, with further development, could provide a lowcost, customizable, scalable and quick-to-print platform for drug screening and to study neuromuscular junction physiology and pathogenesis.

Supplementary Materials: The following are available online at https://www.mdpi.com/2227-9 059/9/1/16/s1, Figure S1: Comparison of FTIR spectra of extracted marine-derived collagen with (dotted line) and without (solid line) methacrylation.

Author Contributions: Conceptualization: G.W., X.L. and Z.Y., Methodology: Z.Y. and K.G., Validation: Z.Y., K.G. and X.L., Investigation: B.S., A.A.S., B.T., Resource: G.W., Writing-Original Draft Preparation: B.T., Writing—Review and Editing: K.G., Visualisation: B.T., K.G., Supervision: G.W., Z.Y., X.L., K.G.; Funding Acquisition: G.W. All authors have read and agreed to the published version of the manuscript.

Funding: The authors acknowledge the financial support of the ARC Centre of Excellence for Electromaterials Science (CE140100012), the International Education and Training program in relation to the project. Ane Albillos Sanchez and Borja Sanz were supported by a BIOFABrication for future Manufacturing and the EU ICI ECP International Joint Program Biofabrication Mobility Grant. Xiao Liu was supported by the ARC Industrial Transformation Training Centre in Additive Biomanufacturing (IC160100026).

Acknowledgments: Gelatin methacryloyl was provided by the Australian National Fabrication Facility (ANFF Materials Node) and the design and development of the BioScribe printer at the Translational Research Initiative for Cell Engineering and Printing (TRICEP), all at the University of Wollongong, New South Wales, Australia. We are indebted to Pia Winberg (Venus Shell Systems) for ongoing insights into marine sources of bioink components. Technical discussions and insights from Malachy Maher (UOW) and John Ramshaw (CSIRO) are also acknowledged.

Conflicts of Interest: The authors declare no conflict of interest.

\section{References}

1. Silva, T.H.; Moreira-Silva, J.; Marques, A.L.; Domingues, A.; Bayon, Y.; Reis, R.L. Marine origin collagens and its potential applications. Mar. Drugs 2014, 12, 5881-5901. [CrossRef] [PubMed]

2. Frantz, C.; Stewart, K.M.; Weaver, V.M. The extracellular matrix at a glance. J. Cell Sci. 2010, 123, 4195-4200. [CrossRef] [PubMed]

3. Rozario, T.; DeSimone, D.W. The extracellular matrix in development and morphogenesis: A dynamic view. Dev. Biol. 2010, 341, 126-140. [CrossRef] [PubMed]

4. Chattopadhyay, S.; Raines, R.T. Collagen-based biomaterials for wound healing. Biopolymers 2014, 101, 821-833. [CrossRef] [PubMed]

5. Patino, M.G.; Neiders, M.E.; Andreana, S.; Noble, B.; Cohen, R.E. Collagen as an implantable material in medicine and dentistry. J. Oral Implantol. 2002, 28, 220-225. [CrossRef]

6. Ferreira, A.M.; Gentile, P.; Chiono, V.; Ciardelli, G. Collagen for bone tissue regeneration. Acta Biomater. 2012, 8, 3191-3200. [CrossRef]

7. Mandrycky, C.; Wang, Z.; Kim, K.; Kim, D.-H. 3D bioprinting for engineering complex tissues. Biotechnol. Adv. 2016, 34, 422-434. [CrossRef]

8. Murphy, S.V.; Atala, A. 3D bioprinting of tissues and organs. Nat. Biotechnol. 2014, 32, 773-785. [CrossRef]

9. Lozano, R.; Stevens, L.; Thompson, B.C.; Gilmore, K.J.; Gorkin, R.; Stewart, E.M.; In Het Panhuis, M.; Romero-Ortega, M.; Wallace, G.G. 3D printing of layered brain-like structures using peptide modified gellan gum substrates. Biomaterials 2015, 67, $264-273$. [CrossRef] 
10. Liu, X.; Carter, S.S.D.; Renes, M.J.; Kim, J.; Rojas-Canales, D.M.; Penko, D.; Angus, C.; Beirne, S.; Drogemuller, C.J.; Yue, Z.; et al. Development of a Coaxial 3D Printing Platform for Biofabrication of Implantable Islet-Containing Constructs. Adv. Healthc. Mater. 2019, 8, 1801181. [CrossRef]

11. Otte, A. 3D Computer-Aided Design Reconstructions and 3D Multi-Material Polymer Replica Printings of the First "Iron Hand" of Franconian Knight Gottfried (Götz) von Berlichingen (1480-1562): An Overview. Prosthesis 2020, 2, 304-312. [CrossRef]

12. Barazanchi, A.; Li, K.C.; Al-Amleh, B.; Lyons, K.; Waddell, J.N. Mechanical Properties of Laser-Sintered 3D-Printed Cobalt Chromium and Soft-Milled Cobalt Chromium. Prosthesis 2020, 2, 313-320. [CrossRef]

13. Claudio-Rizoa, J.A.; Espíndola-Sernab, L.; Becerra-Rodriguezb, J.J.; Cano-Salazara, L.F.; Guíaa, T.E.F. Recent Advances in the Synthesis and Applications of Collagen Based Hydrogels: A Review. Mediterr. J. Basic Appl. Sci. 2019, 3, 54-98.

14. Enea, D.; Gwynne, J.; Kew, S.; Arumugam, M.; Shepherd, J.; Brooks, R.; Ghose, S.; Best, S.; Cameron, R.; Rushton, N. Collagen fibre implant for tendon and ligament biological augmentation. In vivo study in an ovine model. Knee Surg. Sports Traumatol. Arthrosc. 2013, 21, 1783-1793. [CrossRef]

15. Amri, M.; Firdaus, M.; Fauzi, M.; Chowdhury, S.R.; Fadilah, N.; Wan Hamirul, W.; Reusmaazran, M.; Aminuddin, B.; Ruszymah, B. Cytotoxic evaluation of biomechanically improved crosslinked ovine collagen on human dermal fibroblasts. Biomed. Mater. Eng. 2014, 24, 1715-1724. [CrossRef]

16. Perez-Puyana, V.; Romero, A.; Guerrero, A. Influence of collagen concentration and glutaraldehyde on collagen-based scaffold properties. J. Biomed. Mater. Res. Part A 2016, 104, 1462-1468. [CrossRef]

17. Harriger, M.D.; Supp, A.P.; Warden, G.D.; Boyce, S.T. Glutaraldehyde crosslinking of collagen substrates inhibits degradation in skin substitutes grafted to athymic mice. J. Biomed. Mater. Res. Off. J. Soc. Biomater. Jpn. Soc. Biomater. 1997, 35, 137-145. [CrossRef]

18. Chau, D.Y.; Collighan, R.J.; Verderio, E.A.; Addy, V.L.; Griffin, M. The cellular response to transglutaminase-cross-linked collagen. Biomaterials 2005, 26, 6518-6529. [CrossRef]

19. Adamiak, K.; Sionkowska, A. Current methods of collagen cross-linking: Review. Int. J. Biol. Macromol. 2020, 161, 550-560. [CrossRef]

20. Wang, Z.; Tian, Z.; Menard, F.; Kim, K. Comparative study of gelatin methacrylate hydrogels from different sources for biofabrication applications. Biofabrication 2017, 9, 044101. [CrossRef]

21. Nichol, J.W.; Koshy, S.T.; Bae, H.; Hwang, C.M.; Yamanlar, S.; Khademhosseini, A. Cell-laden microengineered gelatin methacrylate hydrogels. Biomaterials 2010, 31, 5536-5544. [CrossRef] [PubMed]

22. Silvipriya, K.; Kumar, K.K.; Bhat, A.; Kumar, B.D.; John, A.; Lakshmanan, P. Collagen: Animal sources and biomedical application. J. Appl. Pharm. Sci. 2015, 5, 123-127. [CrossRef]

23. Subhan, F.; Ikram, M.; Shehzad, A.; Ghafoor, A. Marine collagen: An emerging player in biomedical applications. J. Food Sci. Technol. 2015, 52, 4703-4707. [CrossRef] [PubMed]

24. Easterbrook, C.; Maddern, G. Porcine and bovine surgical products: Jewish, Muslim, and Hindu perspectives. Arch. Surg. 2008, 143, 366-370. [CrossRef]

25. Salvatore, L.; Gallo, N.; Natali, M.L.; Campa, L.; Lunetti, P.; Madaghiele, M.; Blasi, F.S.; Corallo, A.; Capobianco, L.; Sannino, A. Marine collagen and its derivatives: Versatile and sustainable bio-resources for healthcare. Mater. Sci. Eng. C 2020, $113,110963$. [CrossRef]

26. Yoon, H.J.; Shin, S.R.; Cha, J.M.; Lee, S.-H.; Kim, J.-H.; Do, J.T.; Song, H.; Bae, H. Cold water fish gelatin methacryloyl hydrogel for tissue engineering application. PLoS ONE 2016, 11, e0163902. [CrossRef]

27. Iswariya, S.; Bhanukeerthi, A.; Velswamy, P.; Uma, T.; Perumal, P.T. Design and development of a piscine collagen blended pullulan hydrogel for skin tissue engineering. RSC Adv. 2016, 6, 57863-57871.

28. Tylingo, R.; Gorczyca, G.; Mania, S.; Szweda, P.; Milewski, S. Preparation and characterization of porous scaffolds from chitosancollagen-gelatin composite. React. Funct. Polym. 2016, 103, 131-140. [CrossRef]

29. Żelechowska, E.; Sadowska, M.; Turk, M. Isolation and some properties of collagen from the backbone of Baltic cod (Gadus morhua). Food Hydrocoll. 2010, 24, 325-329. [CrossRef]

30. Ahmed, R.; Haq, M.; Chun, B.-S. Characterization of marine derived collagen extracted from the by-products of bigeye tuna (Thunnus obesus). Int. J. Biol. Macromol. 2019, 135, 668-676. [CrossRef]

31. Song, E.; Kim, S.Y.; Chun, T.; Byun, H.-J.; Lee, Y.M. Collagen scaffolds derived from a marine source and their biocompatibility. Biomaterials 2006, 27, 2951-2961. [CrossRef] [PubMed]

32. Teramoto, N.; Hayashi, A.; Yamanaka, K.; Sakiyama, A.; Nakano, A.; Shibata, M. Preparation and mechanical properties of photo-crosslinked fish gelatin/imogolite nanofiber composite hydrogel. Materials 2012, 5, 2573-2585. [CrossRef]

33. El-Rashidy, A.A.; Gad, A.; Abu-Hussein, A.E.-H.G.; Habib, S.I.; Badr, N.A.; Hashem, A.A. Chemical and biological evaluation of Egyptian Nile Tilapia (Oreochromis niloticas) fish scale collagen. Int. J. Biol. Macromol. 2015, 79, 618-626. [CrossRef] [PubMed]

34. Huang, C.-Y.; Kuo, J.-M.; Wu, S.-J.; Tsai, H.-T. Isolation and characterization of fish scale collagen from tilapia (Oreochromis sp.) by a novel extrusion-hydro-extraction process. Food Chem. 2016, 190, 997-1006. [CrossRef]

35. Sousa, R.O.; Alves, A.L.; Carvalho, D.N.; Martins, E.; Oliveira, C.; Silva, T.H.; Reis, R.L. Acid and enzymatic extraction of collagen from Atlantic cod (Gadus Morhua) swim bladders envisaging health-related applications. J. Biomater. Sci. Polym. Ed. 2020, 31, 20-37. [CrossRef]

36. Nagai, T.; Worawattanamateekul, W.; Suzuki, N.; Nakamura, T.; Ito, T.; Fujiki, K.; Nakao, M.; Yano, T. Isolation and characterization of collagen from rhizostomous jellyfish (Rhopilema asamushi). Food Chem. 2000, 70, 205-208. [CrossRef] 
37. Nagai, T.; Ogawa, T.; Nakamura, T.; Ito, T.; Nakagawa, H.; Fujiki, K.; Nakao, M.; Yano, T. Collagen of edible jellyfish exumbrella. J. Sci. Food Agric. 1999, 79, 855-858. [CrossRef]

38. Shanmugam, V.; Ramasamy, P.; Subhapradha, N.; Sudharsan, S.; Seedevi, P.; Moovendhan, M.; Krishnamoorthy, J.; Shanmugam, A.; Srinivasan, A. Extraction, structural and physical characterization of type I collagen from the outer skin of Sepiella inermis (Orbigny, 1848). Afr. J. Biotechnol. 2012, 11, 14326-14337. [CrossRef]

39. Swatschek, D.; Schatton, W.; Kellermann, J.; Müller, W.E.; Kreuter, J. Marine sponge collagen: Isolation, characterization and effects on the skin parameters surface-pH, moisture and sebum. Eur. J. Pharm. Biopharm. 2002, 53, 107-113. [CrossRef]

40. Tziveleka, L.-A.; Ioannou, E.; Tsiourvas, D.; Berillis, P.; Foufa, E.; Roussis, V. Collagen from the marine sponges Axinella cannabina and Suberites carnosus: Isolation and morphological, biochemical, and biophysical characterization. Mar. Drugs 2017, 15, 152. [CrossRef]

41. Zeng, S.-K.; Zhang, C.-H.; Lin, H.; Yang, P.; Hong, P.-Z.; Jiang, Z. Isolation and characterisation of acid-solubilised collagen from the skin of Nile tilapia (Oreochromis niloticus). Food Chem. 2009, 116, 879-883. [CrossRef]

42. Jongjareonrak, A.; Benjakul, S.; Visessanguan, W.; Tanaka, M. Isolation and characterization of collagen from bigeye snapper (Priacanthus macracanthus) skin. J. Sci. Food Agric. 2005, 85, 1203-1210. [CrossRef]

43. Woo, J.-W.; Yu, S.-J.; Cho, S.-M.; Lee, Y.-B.; Kim, S.-B. Extraction optimization and properties of collagen from yellowfin tuna (Thunnus albacares) dorsal skin. Food Hydrocoll. 2008, 22, 879-887. [CrossRef]

44. Okazaki, E.; Osako, K. Isolation and characterization of acid-soluble collagen from the scales of marine fishes from Japan and Vietnam. Food Chem. 2014, 149, 264-270.

45. Muralidharan, N.; Shakila, R.J.; Sukumar, D.; Jeyasekaran, G. Skin, bone and muscle collagen extraction from the trash fish, leather jacket (Odonus niger) and their characterization. J. Food Sci. Technol. 2013, 50, 1106-1113. [CrossRef]

46. Wang, H.; Liang, Y.; Wang, H.; Zhang, H.; Wang, M.; Liu, L. Physical-chemical properties of collagens from skin, scale, and bone of grass carp (Ctenopharyngodon idellus). J. Aquat. Food Prod. Technol. 2014, 23, 264-277. [CrossRef]

47. Bao, Z.; Gao, M.; Fan, X.; Cui, Y.; Yang, J.; Peng, X.; Xian, M.; Sun, Y.; Nian, R. Development and characterization of a photo-crosslinked functionalized type-I collagen (Oreochromis niloticus) and polyethylene glycol diacrylate hydrogel. Int. J. Biol. Macromol. 2020, 155, 163-173. [CrossRef]

48. Wang, J.K.; Yeo, K.P.; Chun, Y.Y.; Tan, T.T.Y.; Tan, N.S.; Angeli, V.; Choong, C. Fish scale-derived collagen patch promotes growth of blood and lymphatic vessels in vivo. Acta Biomater. 2017, 63, 246-260. [CrossRef]

49. Caruso, G. Fishery wastes and by-products: A resource to be valorised. J. Fish. Sci. 2015, 9, 80-83.

50. Yuan, N.; Tian, W.; Sun, L.; Yuan, R.; Tao, J.; Chen, D. Neural stem cell transplantation in a double-layer collagen membrane with unequal pore sizes for spinal cord injury repair. Neural Regen. Res. 2014, 9, 1014.

51. Egawa, E.Y.; Kato, K.; Hiraoka, M.; Nakaji-Hirabayashi, T.; Iwata, H. Enhanced proliferation of neural stem cells in a collagen hydrogel incorporating engineered epidermal growth factor. Biomaterials 2011, 32, 4737-4743. [CrossRef] [PubMed]

52. O'Connor, S.M.; Stenger, D.A.; Shaffer, K.M.; Maric, D.; Barker, J.L.; Ma, W. Primary neural precursor cell expansion, differentiation and cytosolic Ca2+ response in three-dimensional collagen gel. J. Neurosci. Methods 2000, 102, 187-195. [CrossRef]

53. Watanabe, K.; Nakamura, M.; Okano, H.; Toyama, Y. Establishment of three-dimensional culture of neural stem/progenitor cells in collagen Type-1 Gel. Restor. Neurol. Neurosci. 2007, 25, 109-117. [PubMed]

54. Iwashita, M.; Ohta, H.; Fujisawa, T.; Cho, M.; Ikeya, M.; Kidoaki, S.; Kosodo, Y. Brain-stiffness-mimicking tilapia collagen gel promotes the induction of dorsal cortical neurons from human pluripotent stem cells. Sci. Rep. 2019, 9, 1-17. [CrossRef]

55. Fischbach, G.D.; Dichter, M.A. Electrophysiologic and morphologic properties of neurons in dissociated chick spinal cord cell cultures. Dev. Biol. 1974, 37, 100-116. [CrossRef]

56. Cashman, N.R.; Durham, H.D.; Blusztajn, J.K.; Oda, K.; Tabira, T.; Shaw, I.T.; Dahrouge, S.; Antel, J.P. Neuroblastoma x spinal cord (NSC) hybrid cell lines resemble developing motor neurons. Dev. Dyn. 1992, 194, 209-221. [CrossRef]

57. Hunter, D.D.; Cashman, N.; Morris-Valero, R.; Bulock, J.W.; Adams, S.P.; Sanes, J.R. An LRE (leucine-arginine-glutamate)dependent mechanism for adhesion of neurons to S-laminin. J. Neurosci. 1991, 11, 3960-3971. [CrossRef]

58. O'Connell, C.D.; Di Bella, C.; Thompson, F.; Augustine, C.; Beirne, S.; Cornock, R.; Richards, C.J.; Chung, J.; Gambhir, S.; Yue, Z.; et al. Development of the Biopen: A handheld device for surgical printing of adipose stem cells at a chondral wound site. Biofabrication 2016, 8, 015019. [CrossRef]

59. Payne, K.J.; Veis, A. Fourier transform IR spectroscopy of collagen and gelatin solutions: Deconvolution of the amide I band for conformational studies. Biopolymers 1988, 27, 1749-1760. [CrossRef]

60. Surewicz, W.K.; Mantsch, H.H. New Insight into Protein Secondary Structure from Resolution-Enhanced Infrared-Spectra. Biochim. Biophys. Acta 1988, 952, 115-130. [CrossRef]

61. Chadefaux, C.; Le Hô, A.S.; Bellot-Gurlet, L.; Reiche, I. Curve-fitting Micro-ATR-FTIR studies of the amide I and II bands of type I collagen in archaeological bone materials. E-Preserv. Sci. 2009, 6, 129-137.

62. Anand, S.; Kamath, S.; Chuang, L.; Kasapis, S.; Lopata, A.L. Biochemical and thermo-mechanical analysis of collagen from the skin of Asian Sea bass (Lates calcarifer) and Australasian Snapper (Pagrus auratus), an alternative for mammalian collagen. Eur. Food Res. Technol. 2013, 236, 873-882. [CrossRef]

63. Sylvester, M.F.; Yannas, I.V.; Salzman, E.W.; Forbes, M.J. Collagen banded fibril structure and the collagen-platelet reaction. Thromb. Res. 1989, 55, 135-148. [CrossRef] 
64. Pal, P.; Srivas, P.K.; Dadhich, P.; Das, B.; Maity, P.P.; Moulik, D.; Dhara, S. Accelerating full thickness wound healing using collagen sponge of mrigal fish (Cirrhinus cirrhosus) scale origin. Int. J. Biol. Macromol. 2016, 93, 1507-1518. [CrossRef] [PubMed]

65. Brinkman, W.T.; Nagapudi, K.; Thomas, B.S.; Chaikof, E.L. Photo-cross-linking of type I collagen gels in the presence of smooth muscle cells: Mechanical properties, cell viability, and function. Biomacromolecules 2003, 4, 890-895. [CrossRef] [PubMed]

66. Biomatrix, A. Analysis of Type 1 Collagen Products. 2019. Available online: https://advancedbiomatrix.com/sds-banding.html (accessed on 25 December 2020).

67. Ma, X.; Liu, J.; Zhu, W.; Tang, M.; Lawrence, N.; Yu, C.; Gou, M.; Chen, S. 3D bioprinting of functional tissue models for personalized drug screening and in vitro disease modelling. Adv. Drug Deliv. Rev. 2018, 132, 235-251. [CrossRef] [PubMed]

68. Guo, X.; Smith, V.; Jackson, M.; Tran, M.; Thomas, M.; Patel, A.; Lorusso, E.; Nimbalkar, S.; Cai, Y.; McAleer, C.W.; et al. A Human-Based Functional NMJ System for Personalized ALS Modeling and Drug Testing. Adv. Ther. 2020, 3, 2000133. [CrossRef]

69. Natarajan, A.; Sethumadhavan, A.; Krishnan, U.M. Toward Building the Neuromuscular Junction: In Vitro Models To Study Synaptogenesis and Neurodegeneration. ACS Omega 2019, 4, 12969-12977. [CrossRef]

70. 3D Bioprinting and Differentiation of Primary Skeletal Muscle Progenitor Cells; Catherine Ngan, A.Q.; O'Connell, C.; Agdalena KIta, M.; Bourke, J.; Wallace, G.G.; Choong, P.; Robert, M.; Kapsa, I. (Eds.) Springer: New York, NY, USA, 2020; Volume 2140, pp. 229-242.

71. Costantini, M.; Testa, S.; Mozetic, P.; Barbetta, A.; Fuoco, C.; Fornetti, E.; Tamiro, F.; Bernardini, S.; Jaroszewicz, J.; Swieszkowski, W.; et al. Microfluidic-enhanced 3D bioprinting of aligned myoblast-laden hydrogels leads to functionally organized myofibers in vitro and in vivo. Biomaterials 2017, 131, 98-110. [CrossRef]

72. Schuh, C.M.; Day, A.G.; Redl, H.; Phillips, J. An optimized collagen-fibrin blend engineered neural tissue promotes peripheral nerve repair. Tissue Eng. Part A 2018, 24, 1332-1340. [CrossRef]

73. Kotch, F.W.; Raines, R.T. Self-assembly of synthetic collagen triple helices. Proc. Natl. Acad. Sci. USA 2006, 103, 3028-3033. [CrossRef] [PubMed]

74. Novak, U.; Kaye, A.H. Extracellular matrix and the brain: Components and function. J. Clin. Neurosci. 2000, 7, 280-290. [CrossRef] [PubMed]

75. Kim, N.; Burden, S.J. MuSK controls where motor axons grow and form synapses. Nat. Neurosci. 2008, 11, 19-27. [CrossRef] [PubMed]

76. Lin, S.; Maj, M.; Bezakova, G.; Magyar, J.P.; Brenner, H.R.; Ruegg, M.A. Muscle-wide secretion of a miniaturized form of neural agrin rescues focal neuromuscular innervation in agrin mutant mice. Proc. Natl. Acad. Sci. USA 2008, 105, 11406-11411. [CrossRef]

77. Wells, R.G. The role of matrix stiffness in regulating cell behavior. Hepatology 2008, 47, 1394-1400. [CrossRef] 